\title{
Empirical Analysis of Dynamic Linkages between China and International Stock Markets
}

\author{
Thomas C. Chiang ${ }^{*}$, Xiaoyu Chen ${ }^{\dagger}$ \\ ${ }^{1}$ Department of Finance, Drexel University, Philadelphia, PA, USA \\ ${ }^{2}$ Shanghai Stock Exchange, Shanghai, China \\ Email: 'Chiangtc@Drexel.edu,xiaoyuchen@sse.com.cn
}

Received 2 November 2015; accepted 24 February 2016; published 29 February 2016

Copyright (C) 2016 by authors and Scientific Research Publishing Inc.

This work is licensed under the Creative Commons Attribution International License (CC BY). http://creativecommons.org/licenses/by/4.0/

c) (i) Open Access

\section{Abstract}

This paper investigates the dynamic conditional correlations (DCC) of stock returns between China and international markets. Statistics suggest that stock-return correlations across markets are time-varying, displaying a structural change triggered by an upward shift in China's adoption of financial liberalization and the occurrence of the worldwide financial crisis. The dynamic correlations are closely tied to geographic location: the highest correlation is with Hong Kong, followed by Taiwan and Korea; the correlations with Europe and the US are low. The DCC series are negatively associated with the relative $P / E$ ratios and are positively associated with the risk from the US market.

\section{Keywords}

Chinese Stock Market, Smooth Transition, Conditional Variance, DCC Model, Comovements

\section{Introduction}

The success story of Chinese economic growth over the last three decades has been widely reported in various media and in the economic literature. Since 2013, China has been the largest trading country in the world market and is expanding its position in international trades. Along with the trade surpluses created through a series of trade and financial liberalizations, China has accumulated a substantial amount of international reserves. This large amount of international reserves not only provides China a solid base from which to foster its capital mar-

${ }^{*}$ Corresponding author

${ }^{\dagger}$ The opinions expressed here are my own and do not represent those of the Shanghai Stock Exchange. 
kets as a vehicle to support economic growth but also creates a wealth effect, which means that investors demand more investment opportunities to pursue higher returns. The escalating growth in financial assets, accompanied by expectations of more technological innovations and output growth, could lead to the conclusion that the Chinese stock market will continue to rise and that Chinese stocks will become one of the main international financial instruments being absorbed into investors' portfolios.

Indeed, the launch of the "stock connect" link between the Shanghai and Hong Kong stock exchanges on November 17, 2014, removes the traditional restrictions on holding stocks across borders by international investors and Chinese households. The Shanghai-Hong Kong stock connect increases portfolio choices for international investors, because it adds more than 800 companies with market capitalization of US\$1 billion or more to the investment universe. For Chinese households, this scheme provides more investment instruments with which to carry out their saving plans; otherwise, their balance sheets would remain skewed toward a narrow choice of real estate or cash equivalent channels. ${ }^{1}$ With this new market development, it becomes more meaningful to investigate the dynamic stock return relations between China's and Hong Kong's stock markets as well as between China and other international markets. This is not the first study to conduct an investigation of the dynamic relations between China and international markets [1]. However, over time, new schemes are introduced, new policy is implemented, and exogenous shocks occur, therefore, the nature of the dynamic changes and an updated investigation becomes necessary.

To gain some insights into stock market conditions, in Figure 1 we plot the time series of the stock price indices of the Chinese market and other international markets over time. Two sub-sample periods are worthy of comment. First, over the period 3/24/2000-3/11/2003, when most countries, such as the US, European and other Asian countries, suffered big losses (35.47\% - 53.76\%) and a fear of economic recession, Chinese stocks, on the contrary, gained steady growth, amounting to a $100.29 \%$ appreciation in prices. Since then, Chinese stocks have continued to soar, achieving a historical high of 6092.06 points on October 16, 2007, with a gain of $716.26 \%$. However, a year later, as the US financial crisis was propagated to world markets, the Shanghai stock index plummeted to an all-time low of 1706.7 on November 4, 2008, dropping $71.98 \%$, far worse than any other market. Second, during the post-financial-crisis period, the Shanghai stock index declined from 3634.98 on 8/3/2009 to 2134.06 on 7/10/2014, while correspondingly, the stock index in Hong Kong $(20,807.25$ - 23,238.99), following the US markets (S\&P $500=1002.63$ - 1964.68, DJ = 8285.56 - 16,915.07), appreciated substantially over the same sample period. The movements in the Chinese markets reveal two different phases vis-a-vis the global markets. In both sample periods (3/24/2000-3/11/2003 and 8/3/ 2009-7/10/2014), Chinese stocks move inversely with those of global markets. This characteristic conforms to investors' notion of holding Chinese stocks as internationally diversified assets.

By looking at the stock price movement in the Chinese market against the alternative markets in Figure 1, a number of issues deserve our attention. First, with the exceptions of the above two periods when Chinese stock

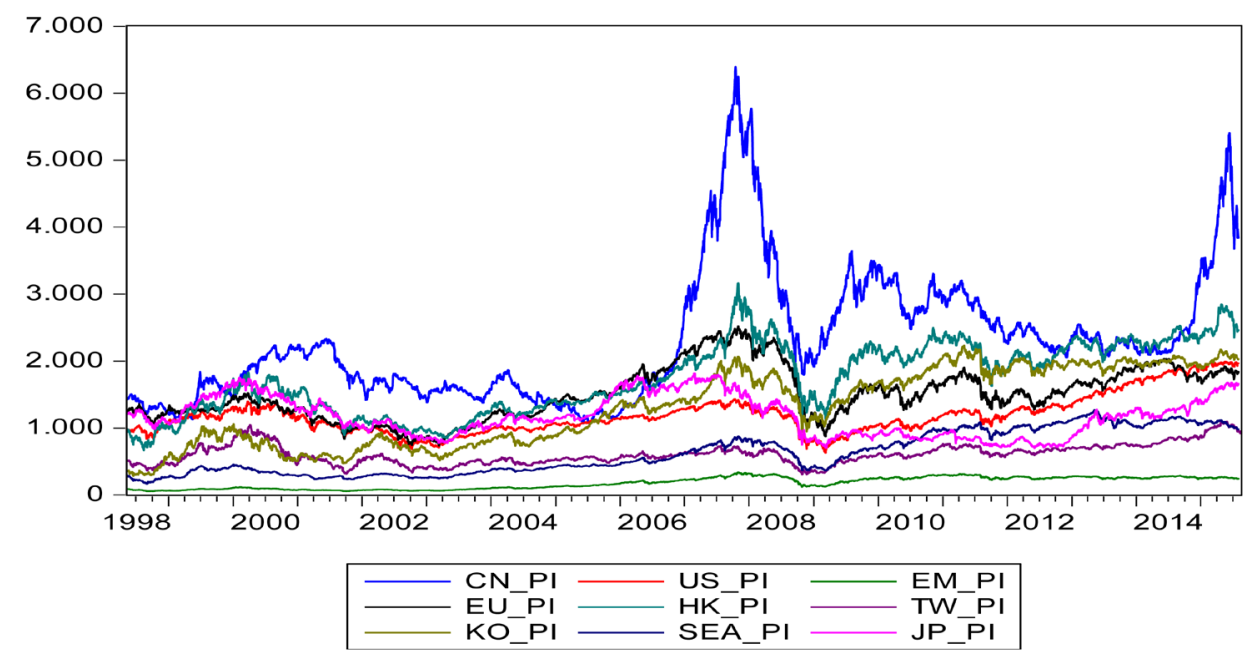

Figure 1. Daily international market stock price indices: 5/12/1998-7/31/2015.

${ }^{1}$ [7] provides a summary of the report. Please refer to: http://www.goldmansachs.com/our-thinking/pages/stock-connect/report.pdf. 
prices moved in the opposite direction, most of the time the Chinese market seems to display co-movement with international markets. Thus, there is less clear-cut correlation between China and international stock prices over the entire sample period. Second, besides the time-varying nature of stock prices, these price series might undergo a structural change. Thus, it is of interest to investigate whether the evolution of the price series demonstrates structural changes. The follow-up questions are: what is the timing for the structural shift and what model would be appropriate to describe the structural shift in prices? Third, in their investigation of a group of advanced markets, [2] finds that international markets are growing more interdependent and that the correlations become more significant within the same geographical region over time. A comparable question here is whether the Chinese equity market in its interactions with international markets follows a similar pattern; that is, do correlations become more significant within a geographical region? It follows that in this study, we focus on the dynamic correlations between the Chinese equity market and its major neighboring markets in Asia. For comparison, we also include both the US and European markets, since these two economies are the major trading partners in the commodity and financial services areas and play a crucial role in promoting the technological transformation and financial modernization of the Chinese economy.

Motivated by the issues outlined above, this study examines stock market behavior unique to the Chinese market. To provide a succinct focus, we raise the following questions that help us to set up testable hypotheses and to perform empirical analyses. First, we shall construct a return series for each market in order to achieve stationarity. Then we will ask: given a series of financial liberalizations, do the Chinese stock market's correlations with the global markets increase? Second, does the structural change present a level shift or a smooth transitional move? Third, are the variations in the dynamic correlation of stock returns over time associated with differences in economic fundamentals? If yes, what are the relevant economic fundamentals? Fourth, what is the role of interest rate policy in explaining the dynamic correlation of stock returns? Fifth, are dynamic correlations identical across different countries? If so, what factors may contribute to differences in dynamic correlation behavior? Is it due to geographical factors? To address these questions, this study examines stock market behavior based on aggregate stock indices. The evidence derived from the empirical analyses will shed some light on understanding the time-varying behavior of stock return correlations between China and international markets.

The remainder of the paper is organized as follows. Section 2 provides a brief review of the co-movement literature. Section 3 presents a multivariate (A)GARCH model to derive dynamic conditional correlations. Section 4 describes the data and discusses the related statistics in this study. Section 5 analyzes the dynamic correlation path by fitting a step function based on the scheme of the qualified foreign institutional investors as well as a logistic smooth transition model. In this section, we also present evidence of fitting the related models. Section 6 examines the correlation variations by using relative $\mathrm{P} / \mathrm{E}$ ratios and the implied volatility. Section 7 contains summary and conclusions.

\section{Literature on International Market Linkages}

Many research studies have been devoted to examining stock market linkages. The literature can be briefly categorized into the following groups. The first group focuses on market spillovers due to international financial contagion. Earlier research papers by [2]-[4] report evidence of unconditional correlations of stock returns across national markets. However, the results presented by [5] [6] find no significant correlations across countries after accounting for heteroscedasticity. One difficulty with the above models is their inability to recognize the time-varying nature of the conditional correlations. In fact, the correlations of stock returns are subject tochange owing to ongoing exogenous shocks and/or changes in market expectations.

Following [7]-[10] apply Engle's DCC model to investigate the financial contagion of Asian markets during the Asian crisis of 1997-1998 and find that financial contagion is present in the region. In a related study, [11] discovered that the contagion effect is short-lived for the Asian crisis. In a separate study of the dynamic conditional correlations of Brazil, Russia, India, and China (BRIC), [12] confirms that a contagion effect propagates from the crisis country to international markets and that emerging BRIC markets are more prone to financial contagion. The evidence seems to show some contagion and some interdependence. The divergence in the estimating results, to some extent, depends on the length of the time series data and the use of econometric methods (see [13] [14]).

The second group of studies emphasizes the impact of the US market on the world market due to the economic power and dominant financial strength of the US (see [5] [9] [14]). Evidence suggests that the correlations among international stock markets and that the degree of international co-movements among stock indices increased substantially in the post-October 1987 crisis period. [1] tests the stock markets of Thailand, Taiwan, 
Japan, Singapore and Hong Kong and find evidence that these countries are highly dependent on the US market. Similarly, [15] reports that the US stock market plays a leading role in international markets over both the short and the long run. An important message to draw from these studies of international stock price linkages is that if the degree of correlation is high, the US will have significant power to dictate prices in international markets, and the likelihood of achieving international diversification tends to diminish. However, if the correlations are low, the global markets will offer investors an opportunity to achieve the benefit of diversifying their holdings of international stocks. Thus, it is important to examine whether China's stock market index co-moves with those of the US and other international market. ${ }^{2}$

While a large number of articles are devoted to empirical studies of cross-market correlations, including market integration, financial contagion, global volatility spillovers, and co-movements in stock returns, it is not our intention to examine all of these issues. Rather, this paper focuses on the Chinese equity market and examines its dynamic movement with some major Asian markets. We also include both the US and the European and markets in order to verify the geographic hypothesis of correlation co-movements. Since China is a new player in the global stock market, a role driven by the country's rapid economic growth, trade surpluses, financial asset accumulation, and enhancement of global connections, it is of interest to study the profile of the Chinese stock market and the timing of its dynamic correlations with global markets.

Centering on the Chinese market, numerous studies have examined the linkages between the Chinese stock market and international markets. For instance, [16] conducts a correlation study and find no significant evidence to support the causal patterns of stock returns between the Shanghai and Hong Kong markets. [17] presents a GARCH $(1,1)$ regression model and find a negative correlation between the Chinese A-share markets (both the Shanghai and Shenzhen markets) and the Hong Kong market during the Asian crisis period (10/22/ 1997-12/29/1998). Similarly, [18] finds weak linkages in stock returns, but there are no spillovers between Shanghai and Hong Kong. [19] examines the relations between Shanghai and New York stock returns and find no significant correlation. [20] applies daily data from January 2000 to August 2005 to a multivariate GARCH model and finds some significant correlation between Hong Kong's and China's stock markets; however, no comparable evidence supports the finding between China and the US markets. In a recent study, [20] finds evidence of significant correlations between China's and Hong Kong's markets, but no significant support for the correlations between China and the US or European markets. In light of the existing evidence, this paper expands the scope of market coverage, including Hong Kong (HK), South Korea (KR), Taiwan, Japan (JP), Southeastern Asia (SEA), emerging markets (EM), Europe (EURO), and the United States (US). In our study, we present an asymmetric GARCH-dynamic conditional correlation model to examine the nature of stock return correlations and search for appropriate economic factors to examine the variations in correlations. Our evidence suggests that the relative price/earnings (P/E) ratios play a significant role in explaining the conditional return correlations of market return series. That is, the testing result indicates that the correlation of stock returns is negatively related to the magnitude of the relative P/E ratios in the two markets.

\section{The Dynamic Conditional Correlation Model}

Recent studies suggest that Engle's (2002) dynamic conditional correlation model is useful for estimating market linkages in stock returns ([9] [10] [12] [14]), since the model captures dynamic return relations and describes the volatility clustering phenomenon. Moreover, it helps to alleviate the heteroscedasticity problem raised by [5]. Let $\left\{\boldsymbol{R}_{t}\right\}$ be a bivariate return series, expressed as:

$$
\boldsymbol{R}_{t}=\mu_{t}+\varepsilon_{t}
$$

where $\boldsymbol{R}_{t}=\left[R_{1, t} R_{2, t}\right]^{\prime}$ is a $2 \times 1$ vector for stock market returns, and $\varepsilon_{t} \mid \Omega_{t-1}=\left[\varepsilon_{1, t} \varepsilon_{2, t}\right]^{\prime} \sim N\left(0, H_{t}\right), \Omega_{t-1}$ is the information set up to time $t$ - 1 and including time $t-1$. It is convenient to treat $R_{1, t}$ as the return on Chinese stocks and $R_{2, t}$, the stock return in one of the international markets. The $\mu_{t}$ process is to follow the conditional expectation of multivariate time series properties ${ }^{3}$ In the multivariate DCC-GARCH structure, the conditional

${ }^{2}[5]$ investigates the contagion effect by testing whether there is a significant increase in correlations across countries for the crisis period. It tests whether the cross return correlation structure remains unchanged over time using a dummy variable method. However, it is argue that the correlation structure following a smooth transitional process better captures the time series properties and evolution of information.

${ }^{3}$ [7] and [8] form the foundation for this study. This GARCH-MIDAS specification allows researchers to extract a long-run correlation component via mixed data sampling. The shortage of high-frequency observations for the Chinese and other emerging markets prevents us from having the MIDAS touch with mixed frequencies in estimations. 
variance-covariance matrix $H_{t}$ is assumed to be:

$$
H_{t}=D_{t} P_{t} D_{t}
$$

where $D_{t}=\operatorname{diag}\left(\sqrt{h_{11, t}}, \sqrt{h_{22, t}}\right)$ is the $2 \times 2$ diagonal matrix of time-varying standard deviations from univariate models, and $P_{t}$ is the time-varying conditional correlation matrix and satisfies the following conditions:

$$
\begin{aligned}
P_{t} & =\left(Q_{t}^{*}\right)^{-1} Q_{t}\left(Q_{t}^{*}\right)^{-1} \\
\text { where } Q_{t}^{*} & =\operatorname{diag}\left(\sqrt{q_{11, t}}, \sqrt{q_{22, t}}\right) .
\end{aligned}
$$

Now $P_{t}$ in Equation (3) is a correlation matrix with ones on the diagonal and off-diagonal elements less than one in absolute value. The $Q_{t}$ is positive definite and is given by:

$$
Q_{t}=(1-a-b) \bar{Q}+a u_{t-1} u_{t-1}^{\prime}+b Q_{t-1},
$$

where $Q_{t}=\left(q_{i j, t}\right)$ is the $2 \times 2$ time-varying covariance matrix of $u_{t}, \bar{Q}=E\left[u_{t} u_{t}^{\prime}\right]$ is the $2 \times 2$ unconditional variance matrix of $u_{t}$ (where $u_{i, t}=\varepsilon_{i, t} / \sqrt{h_{i, t}}, i=1$ and 2), and $a$ and $b$ are non-negative scalar parameters satisfying $(a+b)<1 .{ }^{4}$ A typical element $\rho_{i j, t}$ of $P_{t}$ in a bivariate case is of the form:

$$
\rho_{12, t}=\frac{q_{12, t}}{\sqrt{q_{11, t}} \sqrt{q_{22, t}}} .
$$

As proposed by [7], the DCC model can be estimated by using a two-stage approach to maximizing the log-likelihood function. ${ }^{5}$

It has been observed that the volatility of stock returns often reacts asymmetrically to negative news than to positive news. Evidence from financial markets suggests that negative shocks to asset prices tend to have a more profound impact on volatility than do positive shocks of the same magnitude [21] [22]. Note that DCC model in [7] has a computational advantage, but no consideration is given to the asymmetric effect of shocks on return volatility. [8] subsequently addresses this issue. The research procedure in this paper will follow the specification of [8] if an asymmetric term is required.

\section{Data}

The data employed in this empirical study include stock indices for advanced markets and some major Asian markets including China. The data cover the daily trading stock indices from May 12, 1998 to July 31, 2015 with a total of 4494 observations, including the Shanghai stock index (China A-shares), the Hang Seng index (Hong Kong), the Taiwan weighted stock index (Taiwan PI) the Korea SE composite index (South Korea), the Tokyo stock index (Japan), the emerging markets stock index, the southeastern Asia market index, the Euro STOXX 50, and the S\&P 500 composite (US). We exclude holidays and outliers from the data. ${ }^{6}$ The inclusion of the markets in this study is based on the justifications of their trading activities with China involving in commodity markets and geographical connection. The starting dates are constrained by the lack of consistently available data for different variables of the markets in Datastream. All of the data are taken from Thomson Reuters' Datastream. We also use the P/E ratio for each market and employ the interest rate change data to measure the easiness of Chinese monetary policy (in Appendix 1), the latter is obtained from the People's Bank of China.

\footnotetext{
${ }^{4} \mathrm{~A}$ typical element of $Q_{t}$ is given by $q_{i j, t}=(1-a-b) \bar{\rho}_{i j}+a u_{i, t-1} u_{j, t-1}+b q_{i j, t-1}$, where $\bar{\rho}_{i j}$ is the unconditional correlation of $u_{i, t} u_{j, t}$. ${ }^{5}$ Let $\theta$ denote the parameters in $D_{t}$, and $\phi$ the parameters in $P_{t}$, then the log-likelihood function is:

$$
I_{t}(\theta, \phi)=\left[-\frac{1}{2} \sum_{t=1}^{T}\left(n \log (2 \pi)+\log \left|D_{t}\right|^{2}+\varepsilon_{t}^{\prime} D_{t}^{-2} \varepsilon_{t}\right)\right]+\left[-\frac{1}{2} \sum_{t=1}^{T}\left(\log \left|P_{t}\right|+u_{t}^{\prime} P_{t}^{-1} u_{t}-u_{t}^{\prime} u_{t}\right)\right] .
$$

The first part of the likelihood function in the above equation is volatility, which is the sum of individual GARCH likelihoods. The log-likelihood function can be maximized in the first stage over the parameters in $D_{t}$. Given the estimated parameters in the first stage, the correlation component of the likelihood function in the second stage (the second part of the above equation) can be maximized to estimate correlation coefficients.

${ }^{6}$ The Chinese market has a longer holiday during the Chinese New Year period. We adjust the other markets in the same way for consistency.
} 
Table 1 provides summary statistics for the stock return data of each market under investigation. The data suggest that the South Korean market has the highest average stock return, accompanied by the highest standard deviation. At the other end, the Japanese market has the lowest return, resulting from the depression in the Japanese stock market since 1994.

Table 2 reports the unconditional correlations between China and the stock returns of seven other markets. The evidence shows that all of the markets demonstrate a positive relationship. Among these markets, the Chinese market has higher correlations with the Asian markets than those of the European and US markets. Clearly, China and Hong Kong have the highest correlation (0.312). This value is lower compared to the earlier finding by [20],

Table 1. Summary statistics of stock returns and correlations of different markets: 5/12/1998-7/31/2015.

\begin{tabular}{cccccccccc}
\hline & CN_RM & US_RM & EU_RM & HK_RM & TW_RM & JP_RM & KO_RM & SEA_RM & EM_RM \\
\hline Mean & 0.013 & 0.016 & 0.008 & 0.022 & 0.013 & 0.008 & 0.041 & 0.027 & 0.022 \\
Median & 0.000 & 0.032 & 0.048 & 0.001 & 0.011 & 0.000 & 0.007 & 0.061 & 0.091 \\
Maximum & 9.439 & 10.902 & 9.468 & 10.592 & 8.957 & 12.292 & 11.388 & 10.444 & 8.957 \\
Minimum & -9.306 & -9.409 & -10.401 & -11.578 & -10.457 & -9.847 & -12.694 & -8.214 & -9.840 \\
Std. Dev. & 1.572 & 1.249 & 1.290 & 1.452 & 1.658 & 1.327 & 1.791 & 1.089 & 1.119 \\
Skewness & -0.112 & -0.222 & -0.262 & -0.104 & -0.012 & -0.367 & -0.138 & -0.344 & -0.712 \\
Kurtosis & 7.824 & 10.645 & 9.182 & 9.156 & 5.732 & 9.033 & 8.167 & 11.080 & 10.556 \\
Jarque-Bera & 4367 & 10,979 & 7205 & 7102 & 1401 & 6915 & 5013 & 12,311 & 11,067 \\
Probability & 0.00 & 0.00 & 0.00 & 0.00 & 0.00 & 0.00 & 0.00 & 0.00 & 0.00 \\
Sum of sq. errors & 11,096 & 7007 & 7475 & 9466 & 12,377 & 7912 & 14,414 & 5323 & 5627 \\
Observations & 4493 & 4493 & 4493 & 4493 & 4505 & 4493 & 4493 & 4493 & 4493 \\
\hline
\end{tabular}

Table 2. Correlations of market stock returns across different markets: 5/12/1998-7/31/2015.

\begin{tabular}{|c|c|c|c|c|c|c|c|c|c|}
\hline \multicolumn{10}{|c|}{ Correlation } \\
\hline t-Statistic & CN_RM & US_RM & EU_RM & HK_RM & TW_RM & JP_RM & KO_RM & SEAA_RM & EM_RM \\
\hline CN_RM & 1 & & & & & & & & \\
\hline \multirow[t]{2}{*}{ US_RM } & 0.038 & 1 & & & & & & & \\
\hline & 2.53 & ---- & & & & & & & \\
\hline \multirow[t]{2}{*}{ EU_RM } & 0.118 & 0.532 & 1 & & & & & & \\
\hline & 7.98 & 42.06 & ----- & & & & & & \\
\hline \multirow[t]{2}{*}{ HK_RM } & 0.312 & 0.188 & 0.413 & 1 & & & & & \\
\hline & 22.01 & 12.80 & 30.43 & ---- & & & & & \\
\hline \multirow[t]{2}{*}{ TW_RM } & 0.157 & 0.108 & 0.204 & 0.433 & 1 & & & & \\
\hline & 10.65 & 7.27 & 13.98 & 32.19 & ----- & & & & \\
\hline \multirow[t]{2}{*}{ JP_RM } & 0.178 & 0.118 & 0.310 & 0.524 & 0.367 & 1 & & & \\
\hline & 12.13 & 7.93 & 21.85 & 41.27 & 26.45 & ----- & & & \\
\hline \multirow[t]{2}{*}{ KO_RM } & 0.146 & 0.146 & 0.303 & 0.551 & 0.449 & 0.479 & 1 & & \\
\hline & 9.86 & 9.92 & 21.31 & 44.20 & 33.67 & 36.54 & ----- & & \\
\hline \multirow[t]{2}{*}{ SEAA_RM } & 0.225 & 0.180 & 0.454 & 0.686 & 0.447 & 0.483 & 0.509 & 1 & \\
\hline & 15.51 & 12.24 & 34.15 & 63.14 & 33.45 & 36.93 & 39.61 & ----- & \\
\hline \multirow[t]{2}{*}{ EM_RM } & 0.087 & 0.438 & 0.709 & 0.674 & 0.552 & 0.499 & 0.616 & 0.735 & 1 \\
\hline & 18.24 & 32.65 & 67.37 & 61.18 & 44.41 & 38.63 & 52.37 & 72.60 & ----- \\
\hline
\end{tabular}

This table reports unconditional correlation coefficients and the corresponding t-statistics of stock returns for pairwise markets. 
since the Chinese stock market persistently declined over the period 2009-2013 (see Figure 1), while the other markets, including Hong Kong, have been moving up with the US market. The higher correlation with the HK market is attributable to its strong economic and business ties with China, sharing business know-how and organizational and institutional settings. The geographical connection and cultural similarity give investors in this region a great deal of advantages in terms of information exchange, processing, and awareness of regulations and transportation costs, which help to promote stock trading.

\section{Estimations of Conditional Correlations}

\subsection{Evidence of Co-Movements}

We estimate the dynamic correlations between China and various international markets by using the (A) DCCGARCH model ([7] [8]) represented by the system of Equations (1)-(7). The estimates reported in Table 3 show that the mean values of daily correlations range from 0.037 (China-US) to 0.322 (China-Hong Kong), with some deviations from the unconditional correlations reported in Table 2. The average conditional correlation with the Hong Kong market has the highest value, accompanied by a high standard deviation. On the contrary, the Chinese and US markets have the lowest correlation, but with less variation (lowest standard deviation), followed by the EU market, implying relatively few linkages with these two markets.

To provide a visual inspection, we present the dynamic trajectory of the conditional correlations in Figure 2. Clearly, the Hong Kong market series displays a higher position and exhibits more volatile fluctuations (0.181) as shown in Table 3. The correlation with the US series, on the other hand, lies below the other markets most of the time. Other markets lie in between these two extremes. In general, all of the conditional correlation series present some degree of upward co-movement around the time of the US financial crisis in 2007.

\subsection{Time Series Factors for Dynamic Correlation Shift}

\subsubsection{Step Function Model}

A look at the trajectory of dynamic correlations in Figure 2 indicates that the correlation series show minor structural changes around 2007. It has been observed that the Chinese government tends to take a gradual approach to liberalizing financial markets. For instance, in order to more closely align China's stock market with those in the global markets, the Chinese government introduced the qualified foreign institutional investor (QFII) and qualified domestic institutional investor (QDII) schemes. ${ }^{7}$ These arrangements provide international financial institutions with a broader opportunity to assess Chinese stock markets. It is anticipated that the implementation of the QFII programs as well as the impact of China's joining the WTO will have some influence

Table 3. A summary of statistics of dynamic correlations between China and international markets.

\begin{tabular}{ccccccccc}
\hline & CN_US & CN_EU & CN_HK & CN_TW & CN_JP & CN_KO & CN_SEA & CN_EM \\
\hline Mean & 0.037 & 0.086 & 0.322 & 0.170 & 0.153 & 0.200 & 0.220 & 0.240 \\
Median & 0.021 & 0.088 & 0.316 & 0.162 & 0.136 & 0.199 & 0.223 & 0.238 \\
Maximum & 0.218 & 0.372 & 0.688 & 0.438 & 0.538 & 0.564 & 0.639 & 0.633 \\
Minimum & -0.041 & -0.215 & -0.593 & -0.337 & -0.079 & -0.118 & -0.465 & -0.383 \\
Std. Dev. & 0.049 & 0.094 & 0.181 & 0.116 & 0.087 & 0.129 & 0.114 & 0.135 \\
Skewness & 1.016 & -0.088 & -0.400 & -0.052 & 0.875 & 0.084 & -0.238 & -0.031 \\
Kurtosis & 3.390 & 2.967 & 3.133 & 2.606 & 3.807 & 2.345 & 3.564 & 2.949 \\
Jarque-Bera & 801.888 & 6.063 & 122.902 & 31.026 & 695.897 & 85.571 & 102.102 & 1.236 \\
Probability & 0.00 & 0.04 & 0.00 & 0.00 & 0.00 & 0.00 & 0.00 & 0.54 \\
Sum Sq. Dev. & 10.639 & 39.774 & 147.280 & 59.960 & 34.311 & 75.302 & 58.818 & 82.185 \\
Observations & 4493 & 4493 & 4494 & 4493 & 4493 & 4493 & 4493 & 4493 \\
\hline
\end{tabular}

a. This table reports a summary of statistics of dynamic conditional correlations of stock returns between China and international markets for the period of 5/12/1998-7/31/2015.

${ }^{7}$ Based on a report by the Shanghai Stock Exchange, a total of 281 qualified foreign institutions were approved for the period from May 23, 2003 through April 8, 2015. 


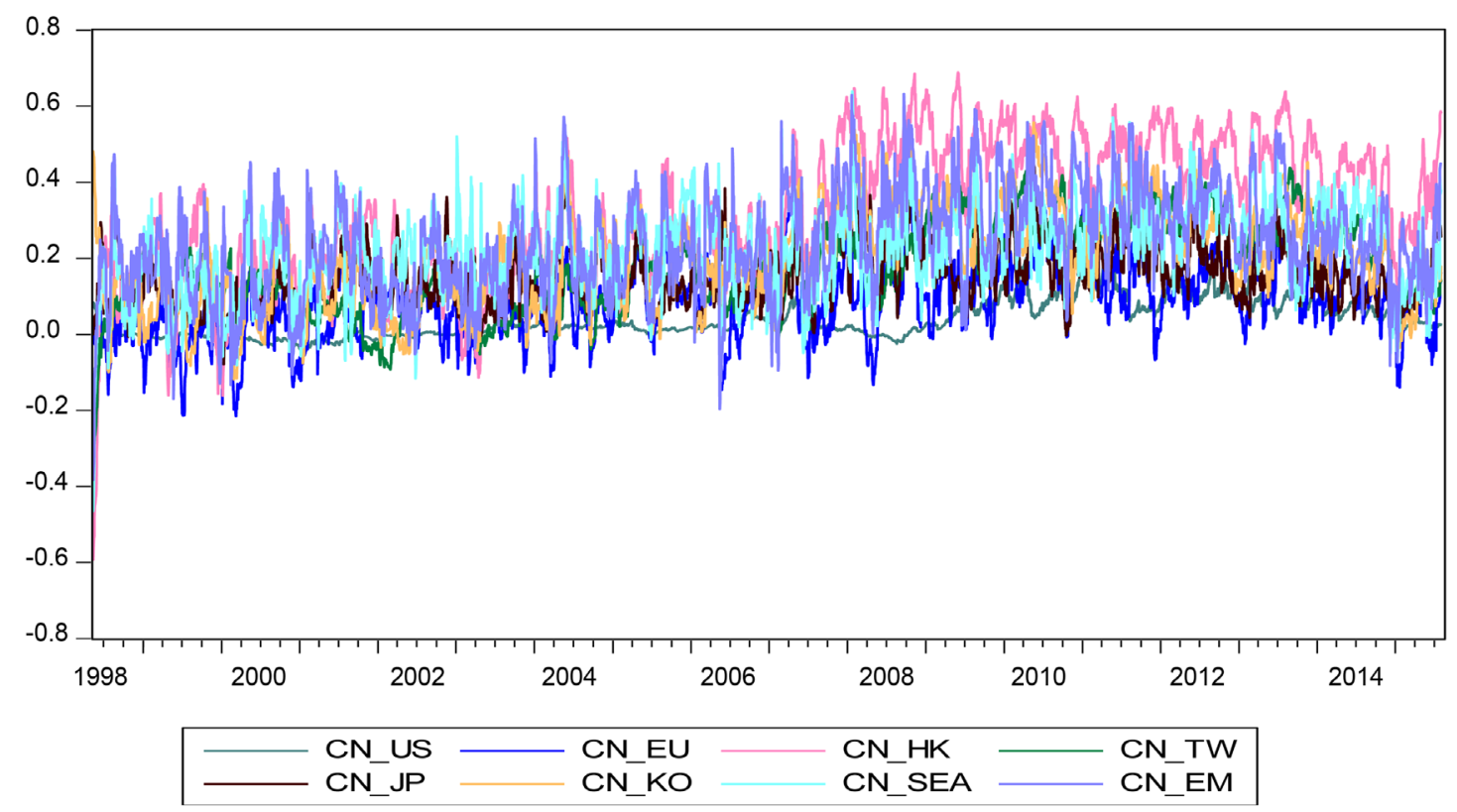

Figure 2. Dynamic conditional correlations of stock returns: China and international markets.

on the structural relations between the two markets' dynamic correlations of stock returns [20] [23]. To model the policy impact, we use the intervention model ([9] [24]) in the form of a step function approach to highlight the effect of policy on the dynamic return correlations. The test equation is given by:

$$
\hat{\rho}_{i, j, t}=\alpha+\beta I_{t}+\varepsilon_{t} .
$$

where $\hat{\rho}_{i, j, t}$ is the conditional correlations of stock returns between $i$ (China) and $j$ (international markets), $I_{t}$ is the indicator variable to capture the presence of QFII, which takes the value of unity, $I_{t}=1$, for the period from May 23, 2003 through April 8, 2015, and 0 otherwise. The starting date of May 23, 2003 is based on the fact that on that date, UBS AG, a global Swiss financial services company, was the first foreign financial institution to meet the qualifications. A total of 281 qualified foreign institutions were approved for the sample period from May 23, 2003 through April 8, 2015. A positive value of $\beta$ represents an upward shift in the correlation series resulting from the implementation of the QFII scheme.

Table 4 reports the regression estimates of the QFII scheme on each market's DCC of stock returns by using the Newey-West consistent estimator. The statistics indicate that the model has some explanatory power, with $R$-squares ranging from 0.0456 to 0.239 . The coefficient of the indicator variable, $\beta$, is positive and highly significant for all of the markets, with an upward shift of 0.239 for the HK market, followed by a 0.1459 shift for the South Korean market; both the US and Japan appear to have low values. The shift in correlation coefficients becomes more apparent as we look at Figure 3(a)-Figure 10(a). Certainly, liberalization of financial restrictions in the Chinese market helps to promote international investment activity, as reflected in an increase in correlated returns. This also brings about transference of risk among investors [25]. The evidence shows that stock markets also present different degrees of co-movement, which may be attributable to different pricing processes, country risk factors, cultural ties, and geographic connections.

Two points in relation to this approach merit comment. First, using the step function model based on the dummy variable approach is useful to highlight a discrete impact of the QFII. This approach, however, is unable to describe the smooth transitional changes resulting from the Chinese liberalization policies during the test period. Second, there is no precise criterion by which to judge whether the transitional point is consistent with the behavioral change in investors. In the above test, all the series are assumed to follow an identical structure for parametric shift; in fact, the recognition and/or adjustment lags could lead to a misspecification of the model.

\subsubsection{Logistic Smooth Transition Model (LSTM)}

To detect a policy effect on market behavior featuring a smoothing process and to detect a precise transitional 
Table 4. Estimates of QFII on dynamic conditional correlations of stock returns: 5/12/1998-4/08/2015.

\begin{tabular}{|c|c|c|c|c|}
\hline Markets & $\alpha$ & $\beta$ & ADF statistic & $R^{2}$ \\
\hline$\hat{\rho}_{C N, U S, t}$ & $\begin{array}{c}-0.0061^{* * *} \\
(5.09)\end{array}$ & $\begin{array}{c}0.0612^{* * *} \\
(21.52)\end{array}$ & $-4.38^{* * *}$ & 0.20 \\
\hline$\hat{\rho}_{C N, E U, t}$ & $\begin{array}{c}0.0222^{* * *} \\
(3.54)\end{array}$ & $\begin{array}{c}0.0900^{* * *} \\
(11.54)\end{array}$ & $-9.39^{* * *}$ & 0.19 \\
\hline$\hat{\rho}_{C N, H K, t}$ & $\begin{array}{c}0.1526^{* * *} \\
(13.99)\end{array}$ & $\begin{array}{c}0.2390^{* * *} \\
(17.59)\end{array}$ & $-7.73^{* * *}$ & 0.36 \\
\hline$\hat{\rho}_{C N, T W, t}$ & $\begin{array}{c}0.0759^{* * *} \\
(27.93)\end{array}$ & $\begin{array}{c}0.1328^{* * *} \\
(41.01)\end{array}$ & $-5.61^{* * *}$ & 0.27 \\
\hline$\hat{\rho}_{\text {CNNP }, t}$ & $\begin{array}{c}0.1206^{* * *} \\
(21.00)\end{array}$ & $\begin{array}{c}0.0456^{* * *} \\
(6.22)\end{array}$ & $-11.42^{* * *}$ & 0.06 \\
\hline$\hat{\rho}_{C N, K O, t}$ & $\begin{array}{c}0.0964^{* * *} \\
(12.23)\end{array}$ & $\begin{array}{c}0.1459^{* * *} \\
(14.47)\end{array}$ & $-8.32^{* * *}$ & 0.26 \\
\hline$\hat{\rho}_{C N, S E A, t}$ & $\begin{array}{c}0.1552^{* * *} \\
(52.78)\end{array}$ & $\begin{array}{c}0.0918^{* * *} \\
(26.27)\end{array}$ & $-14.82^{* * * *}$ & 0.13 \\
\hline$\hat{\rho}_{C N, E M, t}$ & $\begin{array}{c}0.1551^{* * *} \\
(45.37)\end{array}$ & $\begin{array}{c}0.1196^{* * *} \\
(29.45)\end{array}$ & $-12.52^{* * *}$ & 0.16 \\
\hline
\end{tabular}

a. This table presents the estimates of the impact of the QFII and QDII on the conditional correlation time series: $\hat{\rho}_{c, j, t}=\alpha+\beta I_{t}+\varepsilon_{t}$. where $\alpha$ and $\beta$ are constant coefficients, respectively; $\hat{\rho}_{c, j, t}$ is the correlation coefficient between stock returns for market $C(\mathrm{CN})$ and $j(j=\mathrm{HK}, \mathrm{KR}, \mathrm{JP}, \mathrm{EU}, \mathrm{US})$ returns derived from the DCC model; $I_{t}$ is an indicator variable to capture the presence of QFII and QDII, which is set to be unity, $I_{t}=1$, for the period from May 23, 2003 through April 8, 2015, otherwise = 0. A total of 281 qualified foreign institutions were approved for the sample period from May 23, 2003 through April 8, 2015. ADF statistic is the Dickey-Fuller test to examine the unit root of the equation. b. ${ }^{* * *}$, ${ }^{* *}$, and ${ }^{*}$ denote statistical significance at the $1 \%, 5 \%$, and $10 \%$ levels, respectively.

location in the conditional correlation series, we fit the conditional correlation series into a logistic smooth transition regression model (LSTM). Following the specification proposed by [20] [26]-[28], we write:

$$
\begin{gathered}
\hat{\rho}_{i, j, t}=\alpha+\beta S_{t}(\gamma, \tau)+v_{t} \\
S_{t}(\gamma, \tau)=\frac{1}{1+\mathrm{e}^{-\gamma(t-\tau T)}}, \tau>0
\end{gathered}
$$

where $\hat{\rho}_{i, j, t}$ is the conditional correlations of stock returns between $i($ China) and $j$ (international markets) derived from the (A)DCC model ([7] [8]); $v_{t}$ is a zero mean stationary series; $S_{t}$ is the logistic function; $T$ is the sample size; and $\alpha, \beta, \gamma$, and $\tau$ are estimated parameters. In this model, $\hat{\rho}_{i, j, t}$ is assumed to change from an initial value of $\alpha$ to $\alpha+\beta$. Thus, $\alpha$ can be viewed as a measure of regime one in market, and $\alpha+\beta$ as regime 2 . A positive value of $\beta$ indicates an upward shift in regime change (or an increase in linkages). The parameter $\gamma$ determines the speed of the transition between the two regimes. The timing of the transition midpoint, which is the halfway point from regime one to two, is determined by the parameter $\tau$. In particular, the transitional date can be obtained by using $\tau \times T$ (observations).

Table 5 reports the estimated parameters of Equations (8) and (9) and transition midpoint. It can be seen from the estimated statistics that all of the markets exhibit regime changes, shifting from a lower correlation regime to a higher correlation regime, as evidenced by the positive value of $\beta s$, ranging from 0.2897 (HK) to 0.0625 (JP). Interestingly, the level of shifting in general is slightly higher than those obtained by the step-function approach in Table 4. The statistics also suggest that the estimated coefficients of the speed of the transition for all of the markets have positive signs $(\gamma>0)$ and are statistically significant. Particularly, the value of $\gamma$ for the US market (0.029) is the highest, suggesting that the transition toward integration has the faster speed compared with that in other markets. On the contrary, the Japanese market has the slowest movement toward integration, as $\gamma=$ 0.0024. The statistics in Table 4 also indicate that a structural transition occurs around 2007-2009 for most markets, as evidenced by the parameter $\tau$ values from 0.4327 (Korea) to 0.6379 (US). These estimated values of $\tau$ correspond to the time periods 11/21/2005-9/22/2009. It is true that during this time period, the Chinese government adopted a series of financial reforms with more liberal policies, including China's joining the WTO, the 
Table 5. Estimates of LSTM of dynamic correlations based on market data: 5/12/1998-7/31/2015.

\begin{tabular}{|c|c|c|c|c|c|c|c|}
\hline Markets & $\alpha$ & $\beta$ & $\gamma$ & $\tau$ & $\begin{array}{l}\text { Transition } \\
\text { midpoint }\end{array}$ & ADF statistic & $\bar{R}^{2}$ \\
\hline$\hat{\rho}_{C N, U S, t}$ & $\begin{array}{c}0.008^{* * * *} \\
(13.49)\end{array}$ & $\begin{array}{l}0.082^{* * *} \\
(85.56)\end{array}$ & $\begin{array}{c}0.029^{* * * *} \\
(7.36)\end{array}$ & $\begin{array}{l}0.638^{* * * *} \\
(536.09)\end{array}$ & 9/22/2009 & $-4.54^{* * *}$ & 0.63 \\
\hline$\hat{\rho}_{C N, E U, t}$ & $\begin{array}{c}0.053^{* * *} \\
(31.39)\end{array}$ & $\begin{array}{l}0.079^{* * *} \\
(28.81)\end{array}$ & $\begin{array}{c}0.028^{* * *} \\
(5.02)\end{array}$ & $\begin{array}{c}0.583^{* * *} \\
(11.94)\end{array}$ & 5/23/2008 & $-9.26^{* * *}$ & 0.17 \\
\hline$\hat{\rho}_{C N, H K, t}$ & $\begin{array}{l}0.184^{* * *} \\
(73.12)\end{array}$ & $\begin{array}{l}0.289^{* * *} \\
(76.37)\end{array}$ & $\begin{array}{c}0.013^{* * *} \\
(9.76)\end{array}$ & $\begin{array}{c}0.523^{* * *} \\
(265.32)\end{array}$ & $5 / 14 / 2007$ & $-9.95^{* * *}$ & 0.60 \\
\hline$\hat{\rho}_{C N, T W, t}$ & $\begin{array}{l}0.079^{* * *} \\
(39.98)\end{array}$ & $\begin{array}{l}0.193^{* * *} \\
(61.41)\end{array}$ & $\begin{array}{c}0.004^{* * *} \\
(14.72)\end{array}$ & $\begin{array}{c}0.533^{* * *} \\
(131.31)\end{array}$ & 7/18/2007 & $-7.03^{* * *}$ & 0.55 \\
\hline$\hat{\rho}_{C N J P, t}$ & $\begin{array}{c}0.123^{* * *} \\
(7206)\end{array}$ & $\begin{array}{l}0.063^{* * *} \\
(25.63)\end{array}$ & $\begin{array}{l}0.002 \\
(0.00)\end{array}$ & $\begin{array}{l}0.514 \\
(0.16)\end{array}$ & $3 / 14 / 2007$ & $-11.89^{* * *}$ & 0.13 \\
\hline$\hat{\rho}_{C N, K O, t}$ & $\begin{array}{c}0.101^{* * *} \\
(10.32)\end{array}$ & $\begin{array}{l}0.174^{* * *} \\
(12.36)\end{array}$ & $\begin{array}{c}0.004^{* * *} \\
(3.13)\end{array}$ & $\begin{array}{c}0.433^{* * *} \\
(20.74)\end{array}$ & $11 / 21 / 2005$ & $-8.70^{* * * *}$ & 0.33 \\
\hline$\hat{\rho}_{C N, S E A, t}$ & $\begin{array}{l}0.124^{* * *} \\
(759.86)\end{array}$ & $\begin{array}{l}0.064^{* * *} \\
(26.24)\end{array}$ & $\begin{array}{c}0.0026^{* * *} \\
(25.92)\end{array}$ & $\begin{array}{l}0.551^{* * *} \\
(111.36\end{array}$ & $11 / 07 / 2007$ & $-11.94^{* * *}$ & 0.13 \\
\hline$\hat{\rho}_{C N, E M, t}$ & $\begin{array}{c}0.185^{* * *} \\
(87.95)\end{array}$ & $\begin{array}{l}0.120^{* * *} \\
(38.91)\end{array}$ & $\begin{array}{c}0.019^{* * *} \\
(4.06)\end{array}$ & $\begin{array}{c}0.527^{* * *} \\
(122.42)\end{array}$ & 7/22/2008 & $-10.32^{* * * *}$ & 0.26 \\
\hline
\end{tabular}

a. This table presents the estimates of the logistic smooth transition regression model for the conditional correlation time series $\hat{\rho}_{i, j, t}$. The model is given by $\hat{\rho}_{i, j, t}=\alpha+\beta \cdot S_{t}(\gamma, \tau)+u_{t} . S_{t}(\gamma, \tau)=(1+\exp (-\gamma(t-\tau T)))^{-1}, \tau>0$, . where $u_{t}$ is a zero mean stationary series; $S_{t}$ is the logistic function; $T$ is the sample size; and $\alpha, \beta, \gamma$, and $\tau$ are estimated parameters. $t$-statistics in absolute value are given in parentheses. The critical values for the ADF statistic at the $1 \%, 5 \%$, and $10 \%$ levels of significance are $-3.432,-2.862$, and -2.567 , respectively; ${ }^{* * *}$, ${ }^{* *}$, and ${ }^{*}$ denote statistical significance at the $1 \%, 5 \%$, and $10 \%$ levels, respectively. b. The null hypothesis of non-stationarity is rejected by the ADF statistics for all markets. The transition midpoint is obtained by $\tau \times$ 4493(observation).

implementation of the QFII (qualified foreign institutional investors), and the "stock connect" between the Shanghai and Hong Kong stock exchanges. ${ }^{8}$ The catalyst is the global financial crisis, and the highly volatile trading activities that heightened correlations of international stock returns. Thus, the evidence suggests that the outcome of liberal financial policies and the outbreak of the worldwide financial crisis brought about the structural changes in the dynamic correlations.

As part of the modeling process of [26], we test whether the residuals from a smooth transition model are stationary around the trend. By applying the augmented Dickey-Fuller (ADF) test to the residual series after fitting a smooth transition regression model, the ADF statistics in Table 5 indicate that all of the markets are significant at the $1 \%$ level, supporting the use of a smooth transition model.

It is of interest to compare the performances of two types of model specification. The fitted values from the LSTM and residuals are depicted in Figure 3(a)-Figure 10(a), along with Figure 3(a)-Figure 10(a). Two points are worth noting from these figures. First, the transitional point of the dynamic conditional correlation series is better described by the LSTM than by the step regression model, since the structural break-point can be more precisely located and better matched with the time series property. Second, the dynamic structural changes evolve with a smooth transitional process that reflects the combined effects of various financial market res-

${ }^{8}$ On November 10, 2001, the World Trade Organization (WTO) officially approved China's entry as a member (https://www.wto.org/english/thewto_e/countries_e/china_e.htm\#top). The QFII is a program that was launched in 2002 in the People's Republic of China to allow licensed foreign investors to buy and sell yuan-denominated A-shares in China's mainland stocks on the Shanghai and Shenzhen exchanges. As reported by the China Securities Regulatory Commission, the number of licensed QFII investors increased from 12 in December 2003 to 281 on April 8, 2015. On November 17, 2014, the launch of the "stock connect" link between the Shanghai and Hong Kong stock exchanges relaxed the restrictions that historically split the Chinese stock market between shares available to local investors and those available to international investors. 
ponses to policies or external shocks, rather than a single discrete change as presented by the step function model. Obviously, the step function model tends to ignore the lagged effect or smooth transitional process.

Another interesting point we should mention is that among different market linkages, the Hong Kong and Chinese markets present the highest correlation path, sharing the prosperity boom; yet it holds true as one of the markets goes down. Conversely, the Chinese stock market has the lowest correlation with the US market. The low correlation implies that the portfolio combination of US and Chinese stocks is able to achieve the benefits of international diversification. ${ }^{9}$

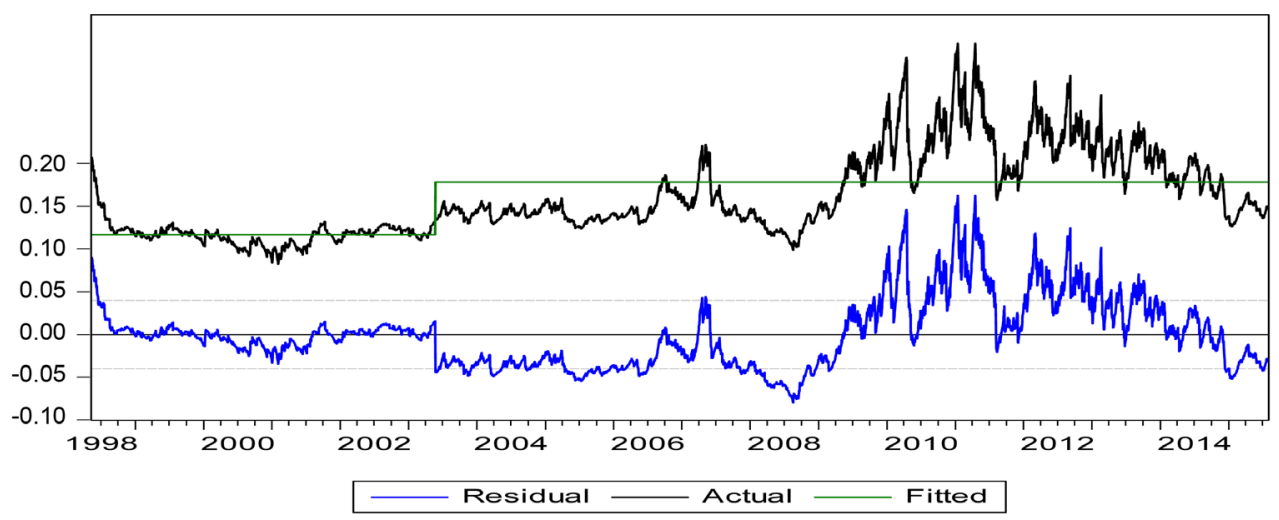

(a)

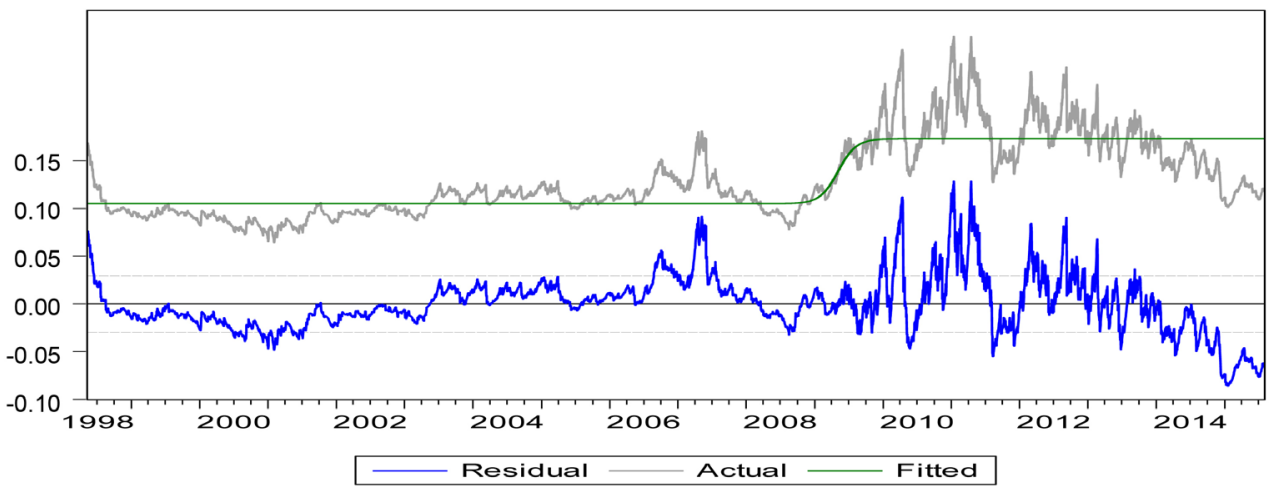

(b)

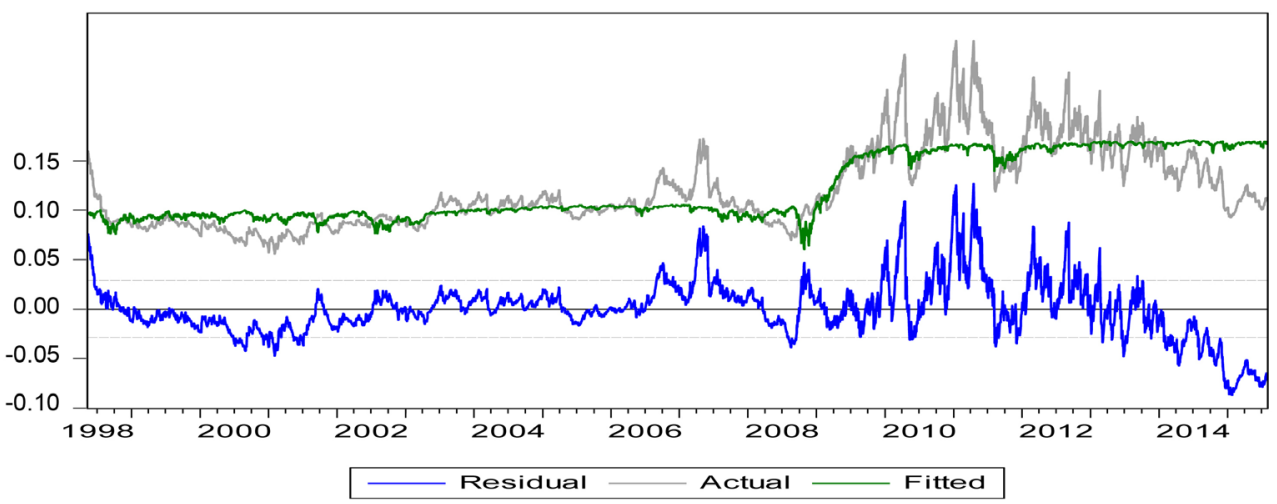

(c)

Figure 3. (a) Impact of QFII on DCC of stock returns: China (CN) and US markets. (b) LSTM estimates of DCC on stock returns: China (CN) and US markets. (c) LSTM-VIX estimates of DCC on stock returns: China (CN) and US markets.

${ }^{9}[29]$ and [20] find low correlations with some sectoral stocks, implying that at the sectoral level, it is also possible to explore the benefits of international diversification despite co-movements prevailing at the market level. 


\section{Economic Factors for Dynamic Correlation Variations}

\subsection{P/E Ratio and Conditional Correlation Variations}

Fitting the correlation series by applying a smooth transition model helps to identify a smoothing regime change and locate the transitional point in time. However, a careful inspection of the residuals after fitting a smooth transition model for each market as shown in Figure 3(b)-Figure 10(b) suggests that no particular economic variable has been used to explain the dynamic conditional correlation variations over time. To address the issue, we shall use the observed P/E ratios between two markets as a proxy for the difference in economic fundamentals. Our decision is based on the observation that, for a market such as China, it is hard to find relevant data for measuring economic fundamentals. Based on our investigation, the majority of stocks are not paying out dividends. For

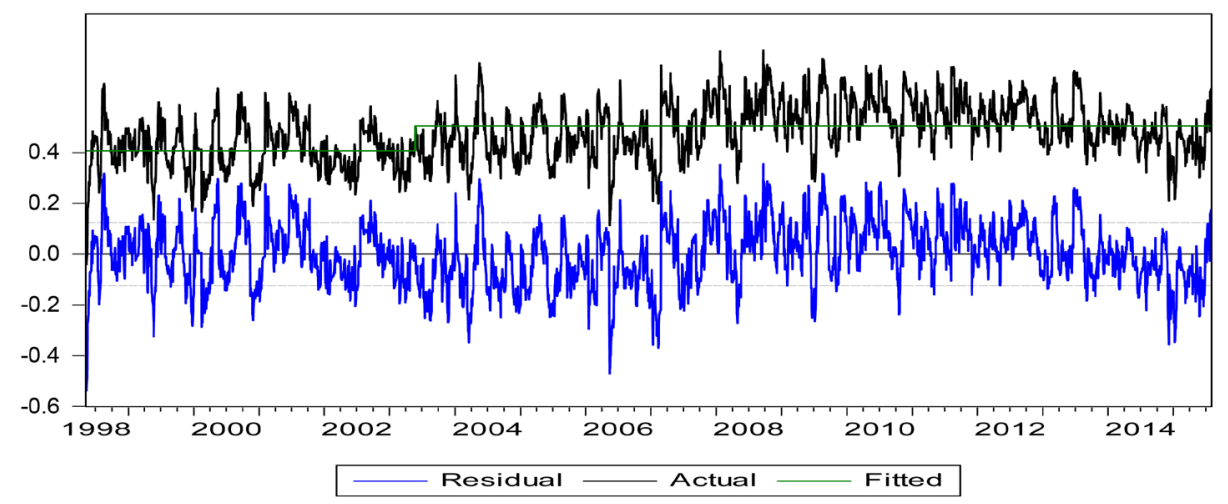

(a)

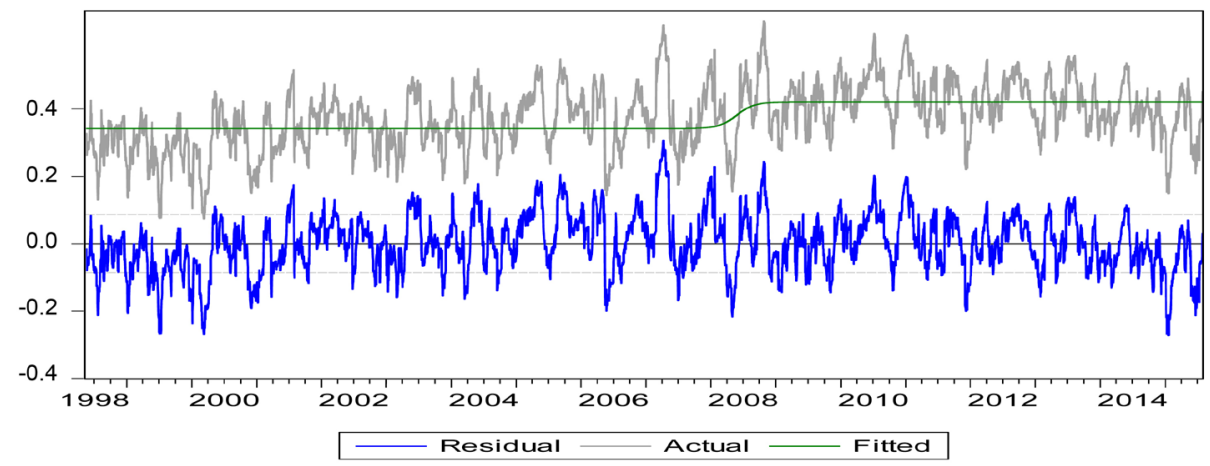

(b)

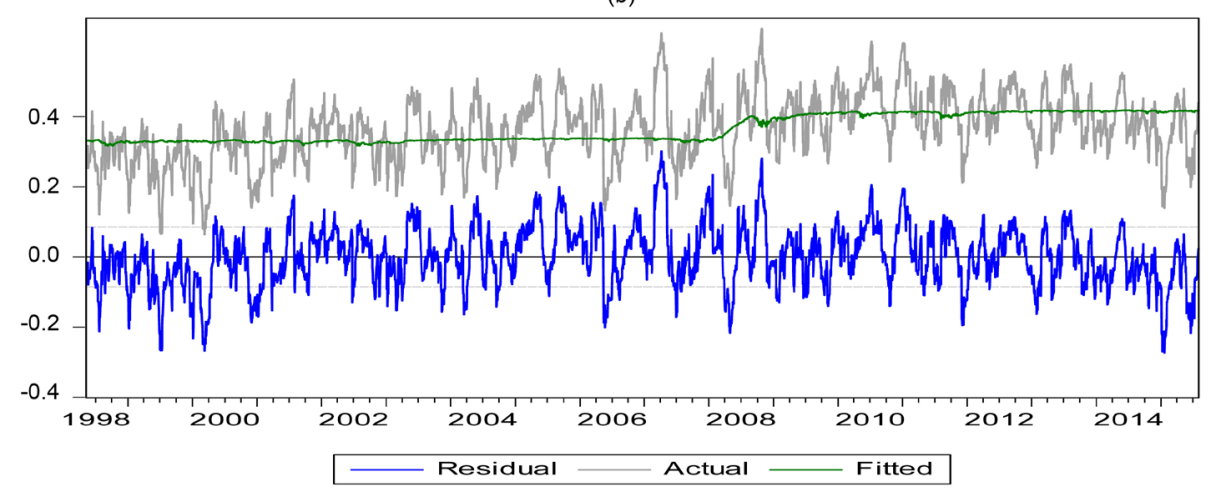

(c)

Figure 4. (a) Impact of QFII on DCC of stock returns: China (CN) and Euro market (EU). (b) LSTM estimates of DCC on stock returns: China (CN) and Euro market (EU). (c) LSTM-VIX estimates of DCC on stock returns: China (CN) and Euro market (EU). 


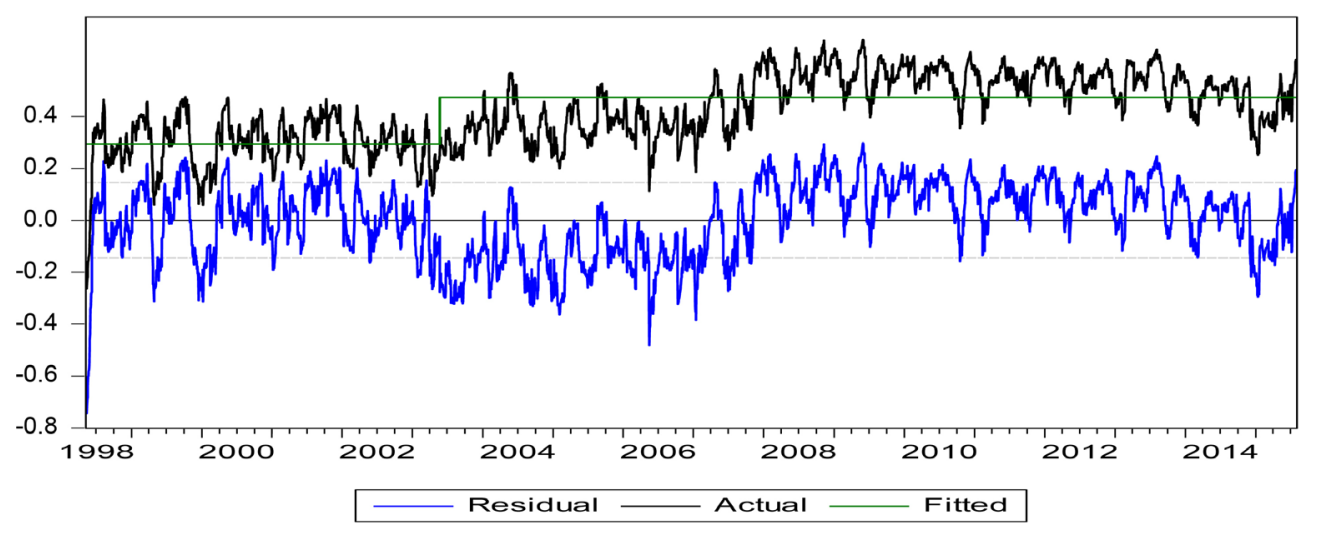

(a)

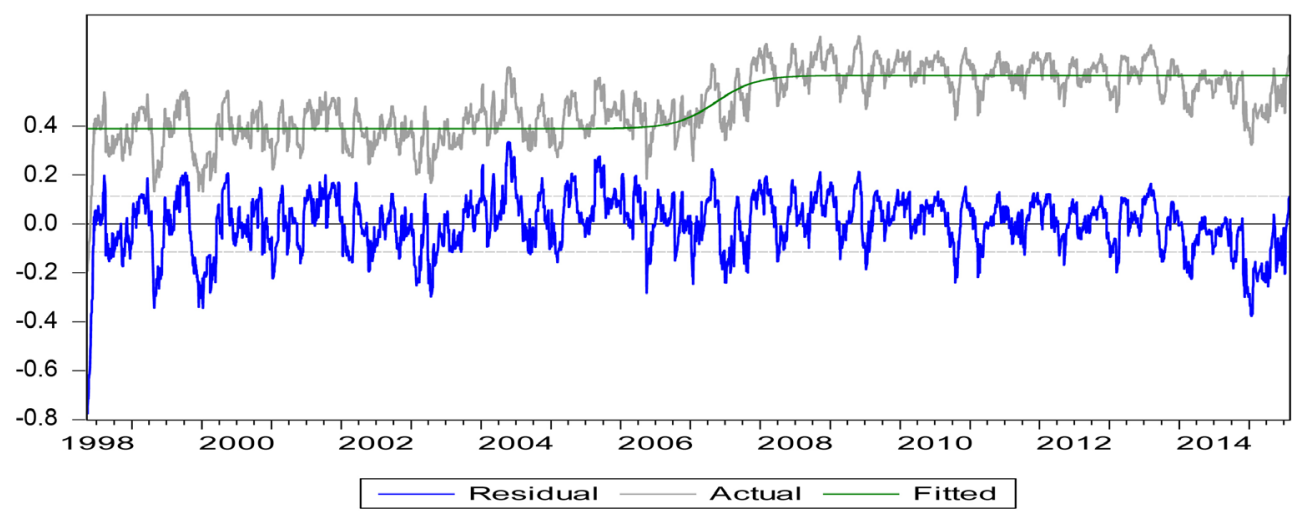

(b)

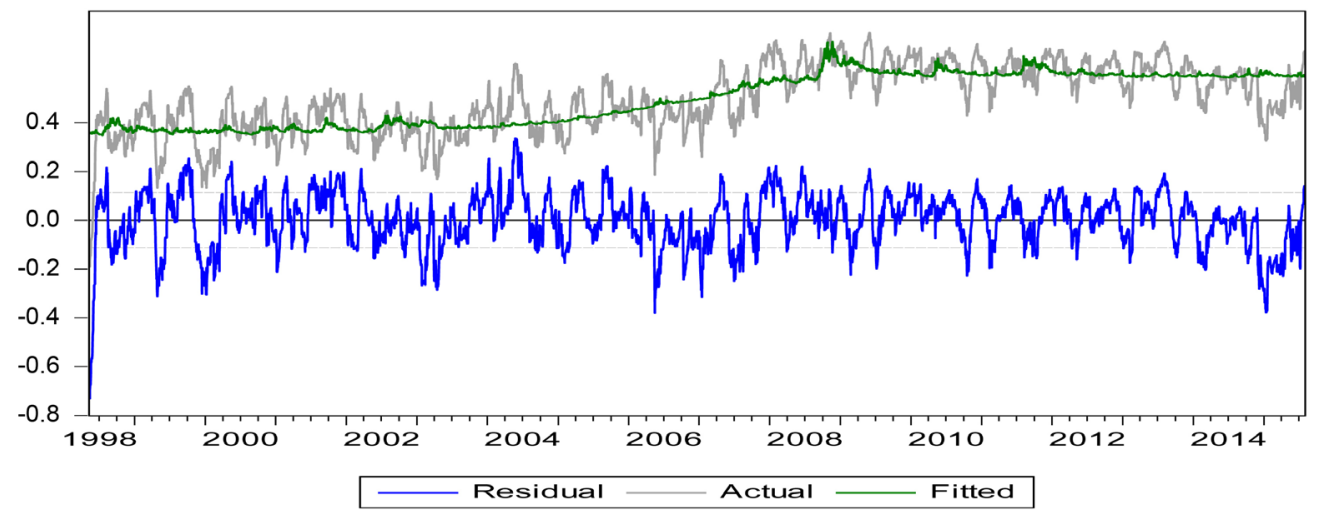

(c)

Figure 5. (a) Impact of QFII on DCC of stock returns: China (CN) and Hong Kong (HK). (b) LSTM estimates of DCC on stock returns: China (CN) and Hong Kong (HK). (c) LSTM-VIX estimates of DCC on stock returns: China (CN) and Hong Kong (HK).

the majority of non-sophisticated investors in China, the P/E ratio is easy to observe and that is sufficient to capture the fundamentals of the stock valuation. As the two P/E ratios move too far away from each other, the high P/E ratio market, such as China, can be interpreted as an out-of-market fundamental base. Thus, the irrational investors that push the $\mathrm{P} / \mathrm{E}$ too high can be seen as a source of risk, causing rational investors to sell off their stocks and trigger price reversion. On the other hand, a stable relation between the high and low P/E ratios can be viewed as a stable state of economic market fundamentals, reflecting a stable correlation between stock returns in the two markets. Thus, we anticipate that the correlation coefficient of stock returns is negatively related to the P/E differential of the two markets. This line of logic leads us to specify: 


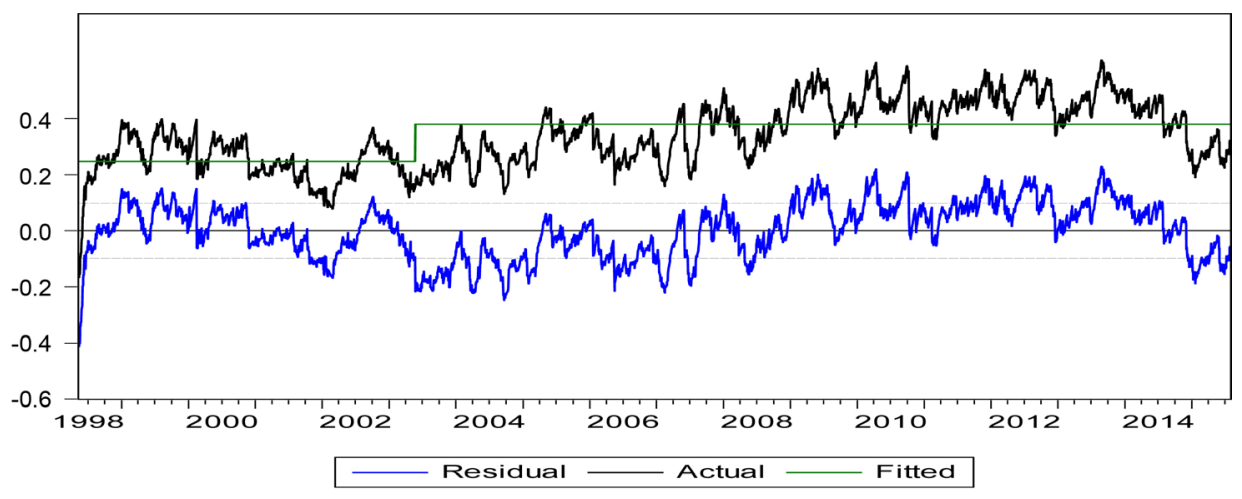

(a)

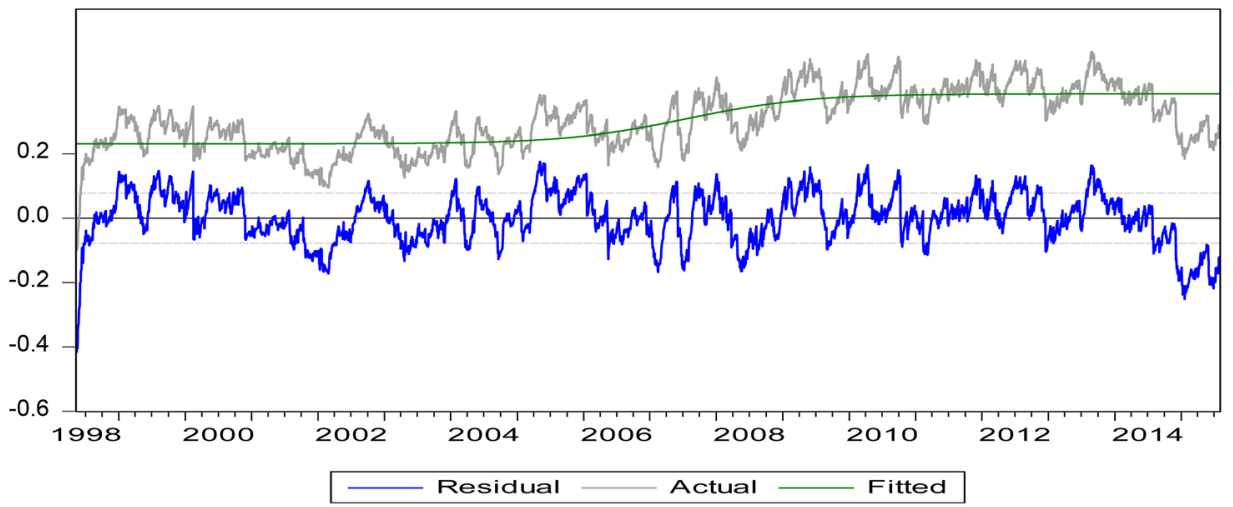

(b)

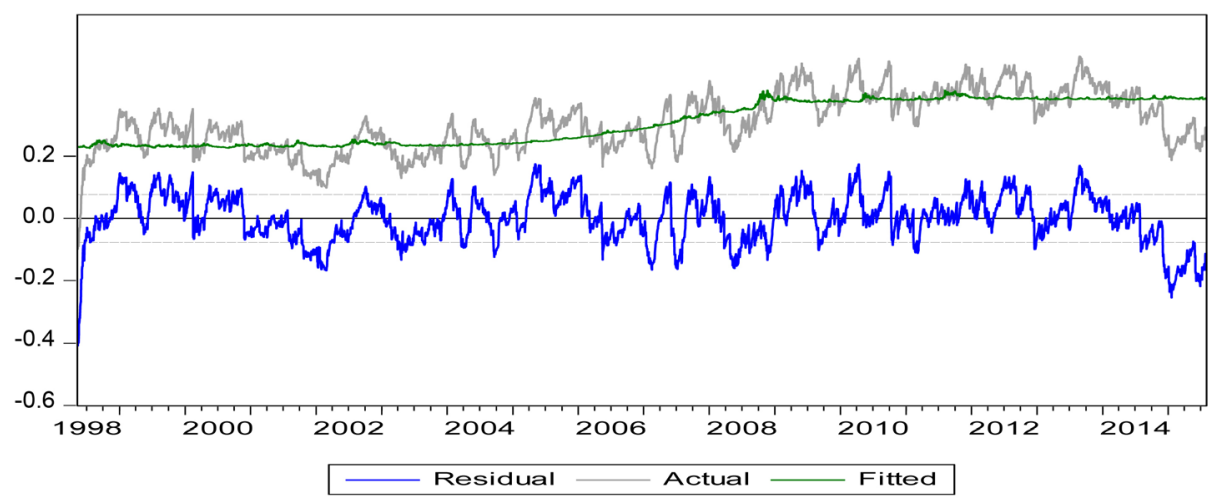

(c)

Figure 6. (a) Impact of QFII on DCC of stock returns: China (CN) and Taiwan (TW). (b) LSTM estimates of DCC on stock returns: China (CN) and Taiwan (TW). (c) LSTM-VIX estimates of DCC on stock returns: China (CN) and Taiwan (TW).

$$
\hat{\rho}_{i, j, t}=\phi_{0}+\phi_{1}\left[\log \left(\frac{P}{E}\right)_{H . t}-\log \left(\frac{P}{E}\right)_{L . t}\right]+\varepsilon_{t}
$$

where $\hat{\rho}_{i, j, t}$ is the conditional correlation for markets $i$ (China) and $j$ (non-Chinese markets) after applying the Fisher transformation on the conditional correlation coefficient; ${ }^{10}\left[\log \left(\frac{P}{E}\right)_{H . t}-\log \left(\frac{P}{E}\right)_{L . t}\right]$ is the $\log$-dif-

\footnotetext{
${ }^{10}$ We apply the Fisher transformation, since some of the correlation coefficients are negative ([9] and [30]).
} 


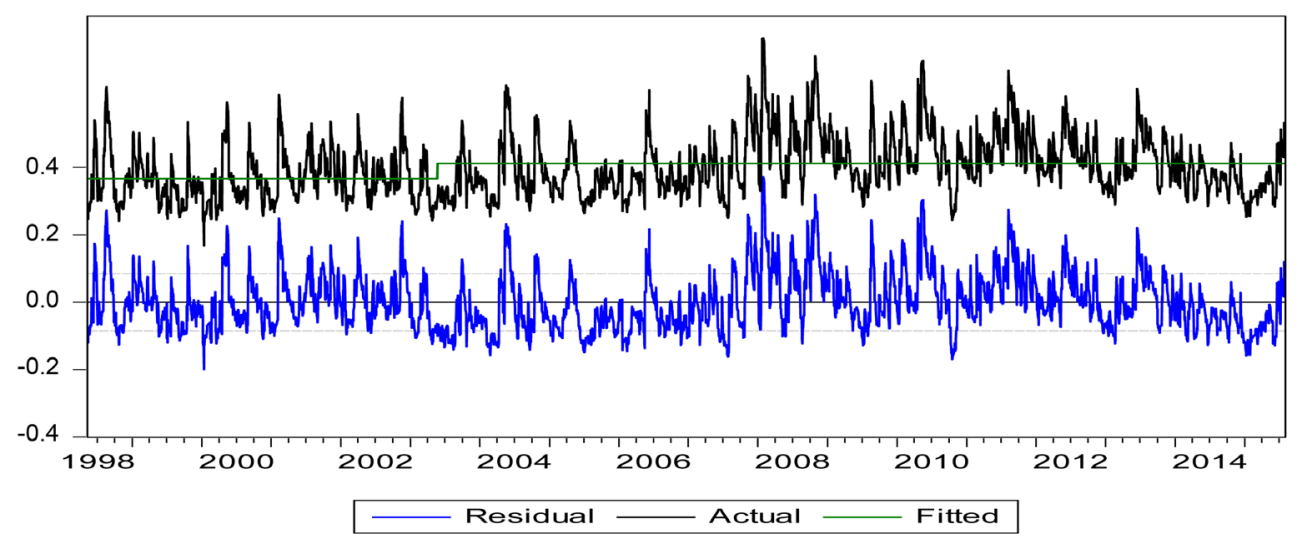

(a)

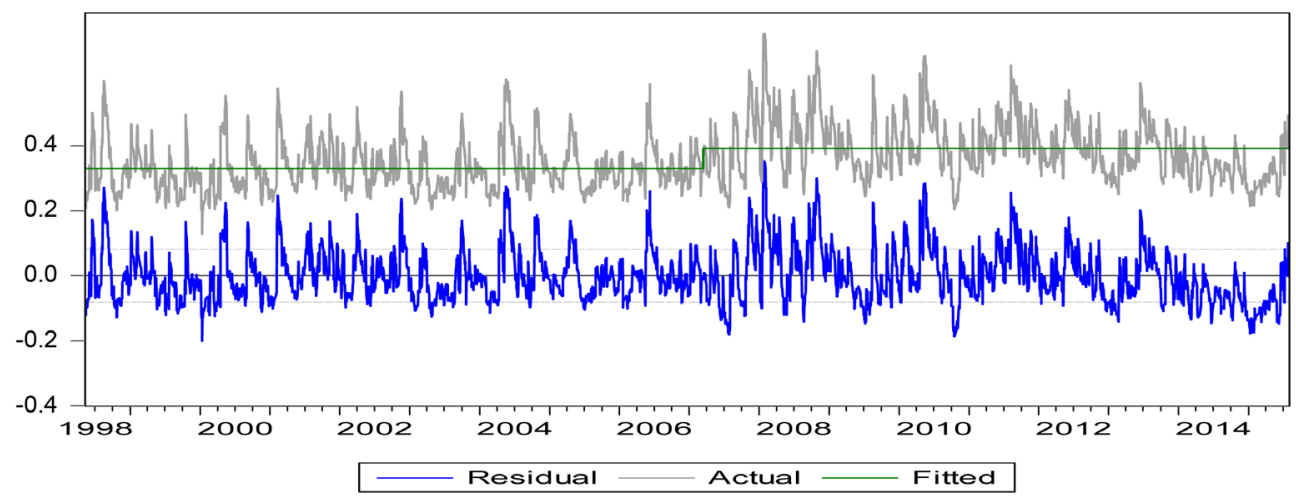

(b)

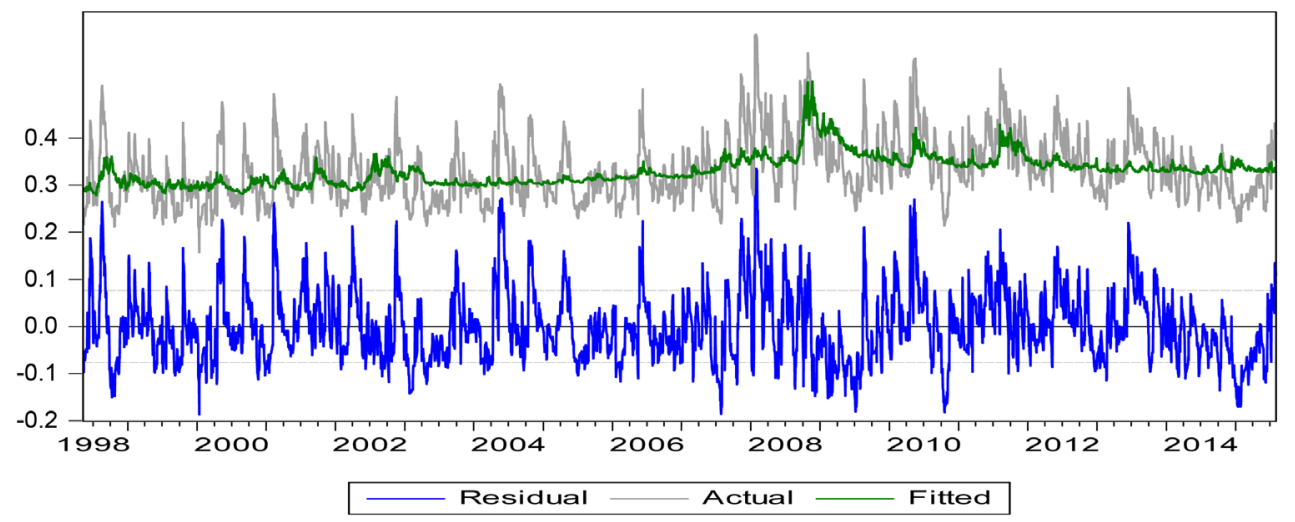

(c)

Figure 7. (a) Impact of QFII on DCC of stock returns: China (CN) and Japan (JP). (b) LSTM estimates of DCC on stock returns: China (CN) and Japan (JP). (c) LSTM-VIX estimates of DCC on stock returns: China $(\mathrm{CN})$ and Japan (JP).

ference of the high and low $\mathrm{P} / \mathrm{E}$ ratios for the two markets. ${ }^{11} \phi_{1}$ is expected to be negative, since an increase in the $\mathrm{P} / \mathrm{E}$ ratio relative to that of a comparable country implies a greater difference in market fundamentals, and investors tend to sell off stocks in the market with excessively higher P/E ratios, leading to a fall in stock prices.

\footnotetext{
${ }^{11}$ In our early empirical experiment, the conditional variances in the exchange rate of the Chinese RMB and different foreign currencies were also included. However, the testing results suggest that most of them are statistically insignificant. One of the main reasons to exclude this variable is that the bilateral exchange rates between China and the markets under investigation do not change frequently enough, especially with respect to Hong Kong's currency. As a result, the inclusion of exchange rate uncertainty does not play a significant role in the test equation.
} 


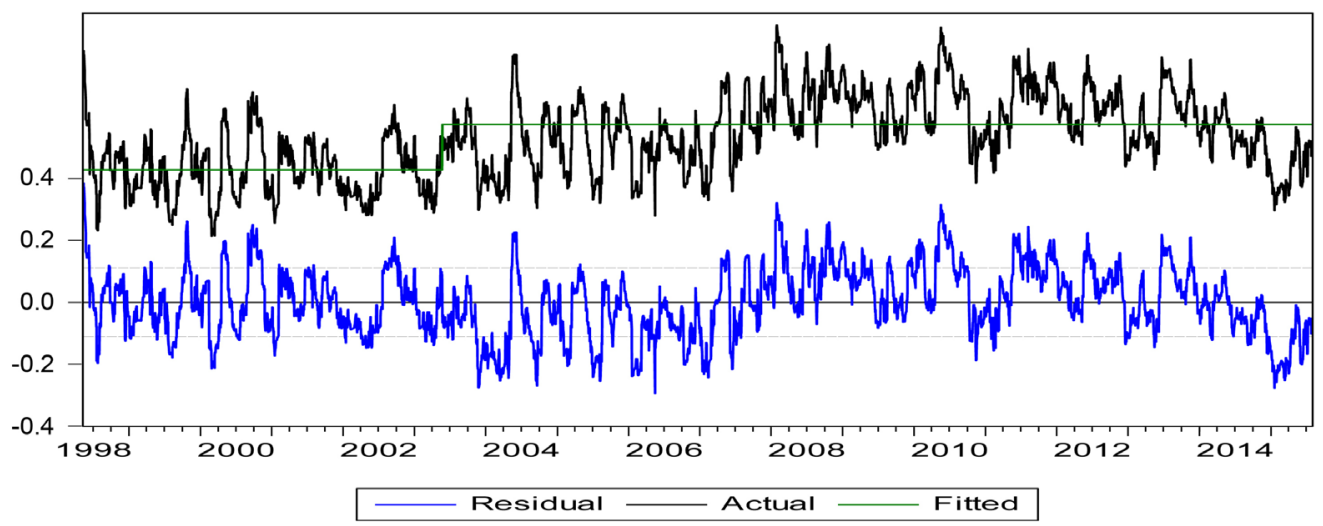

(a)

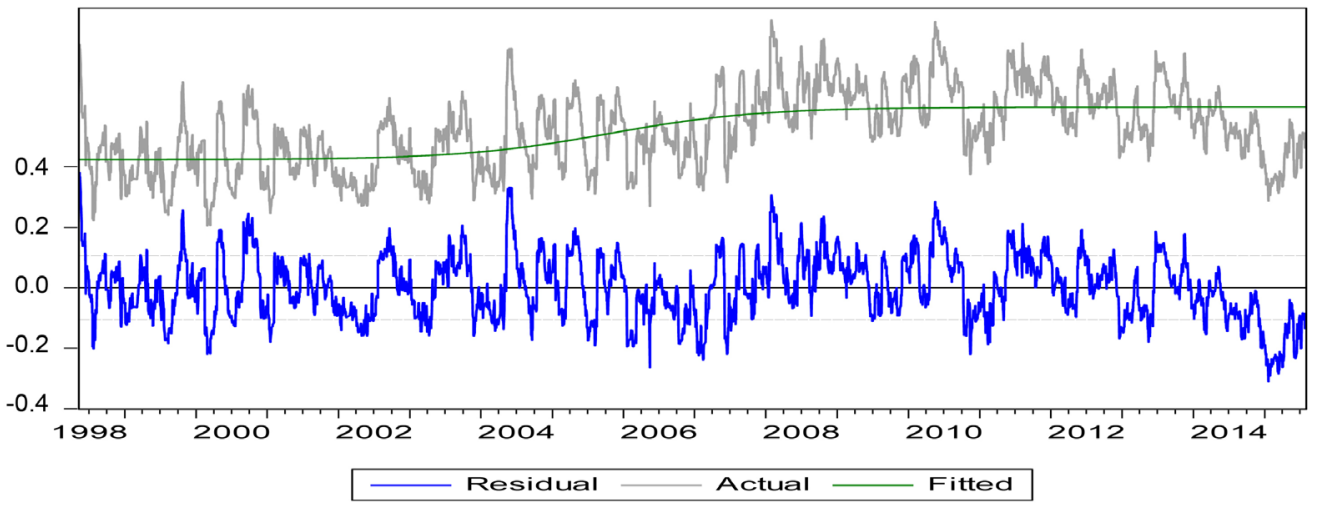

(b)

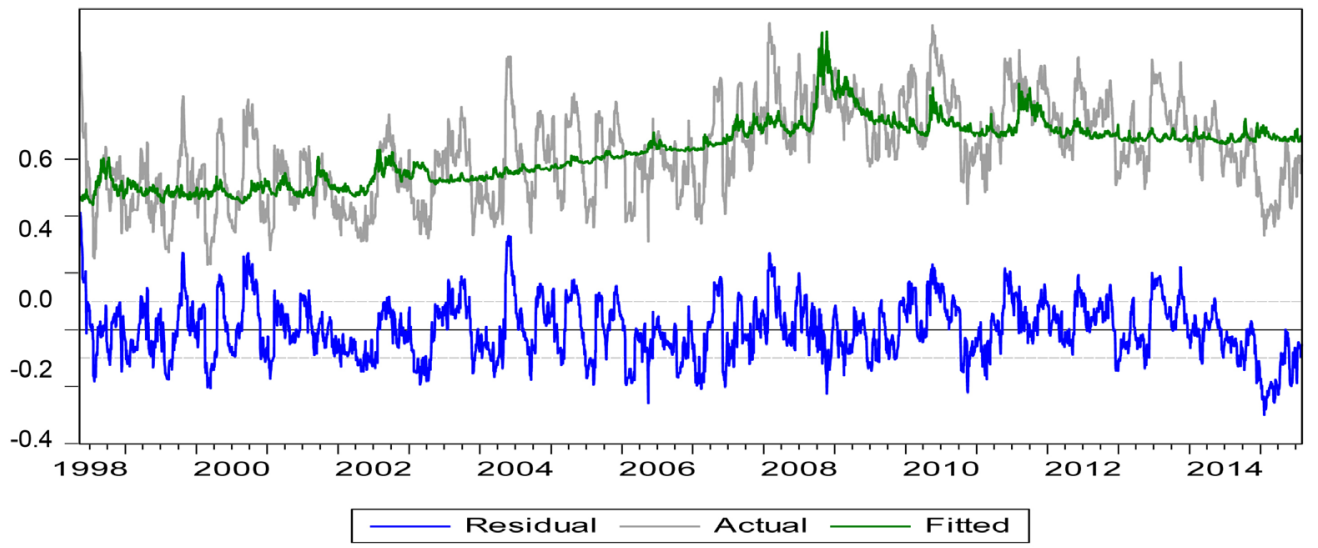

(c)

Figure 8. (a) Impact of QFII on DCC of stock returns: China (CN) and Korea (KO). (b) LSTM estimates of DCC on stock returns: China (CN) and Korea (KO). (c) LSTM-VIX estimates of DCC on stock returns: China (CN) and Korea (KO).

This leads to a reverse correlation of stock returns. Estimates of Equation (10) are reported in Table 6. The evidence suggests that all of the estimated coefficients of the relative P/E ratios have the expected sign and are statistically significant. Note that we should interpret the sign carefully. For the Japanese market, the negative sign applies to the $\left[\log \left(\frac{P}{E}\right)_{J P . t}-\log \left(\frac{P}{E}\right)_{C N . t}\right]$, since the statistics in Table 7, and as shown in Figure 11, indicate that the P/E ratio in the Japanese market (31.639) is higher than that in the Chinese market (24.859); for the other 


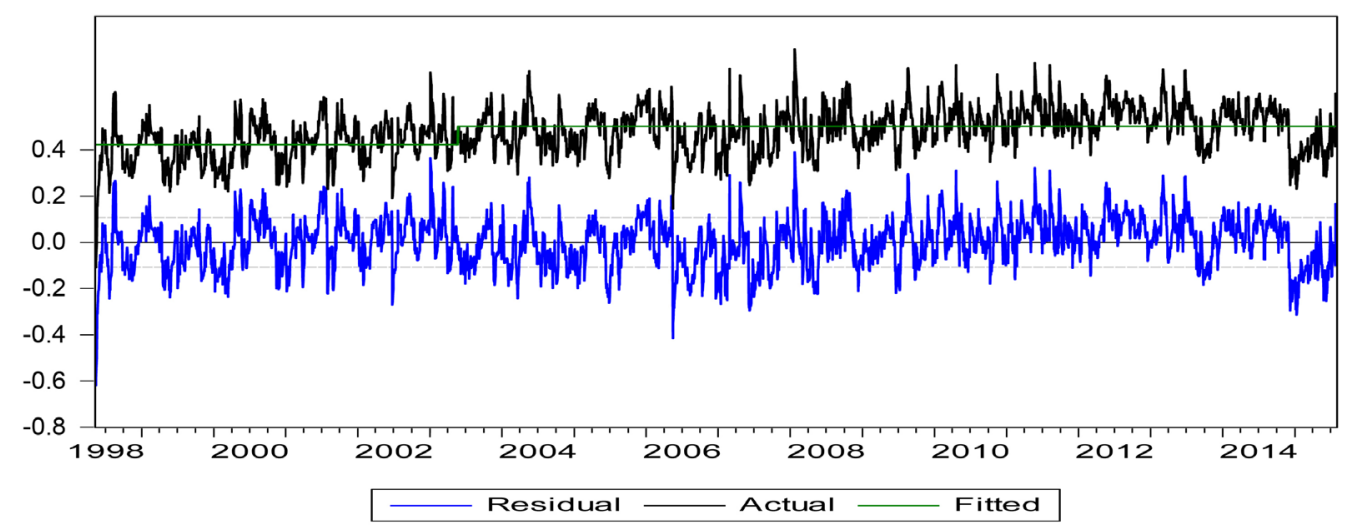

(a)

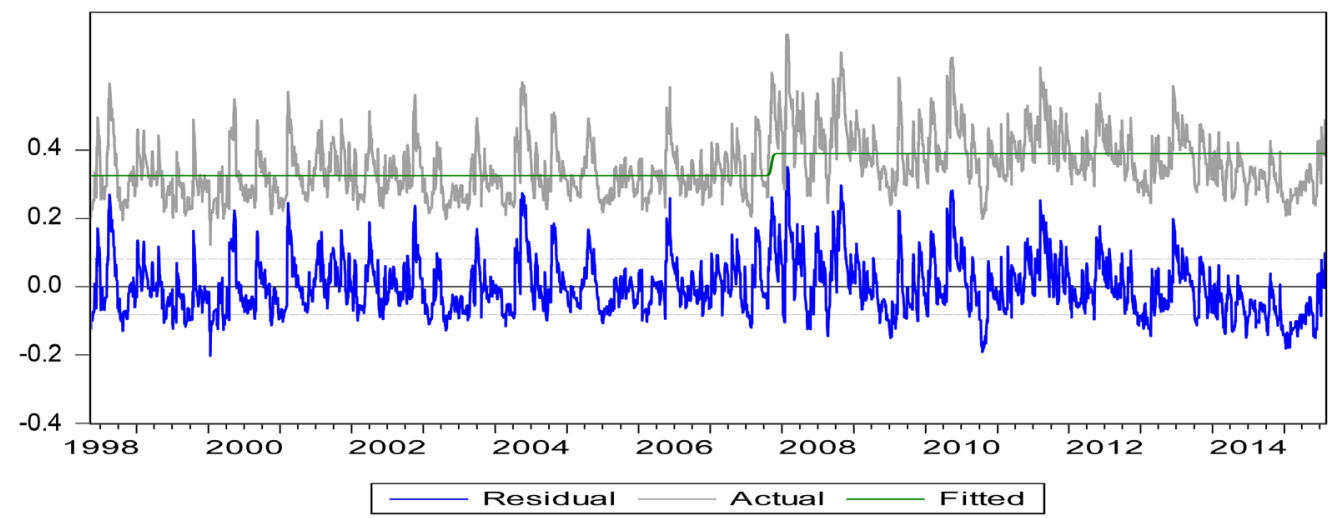

(b)

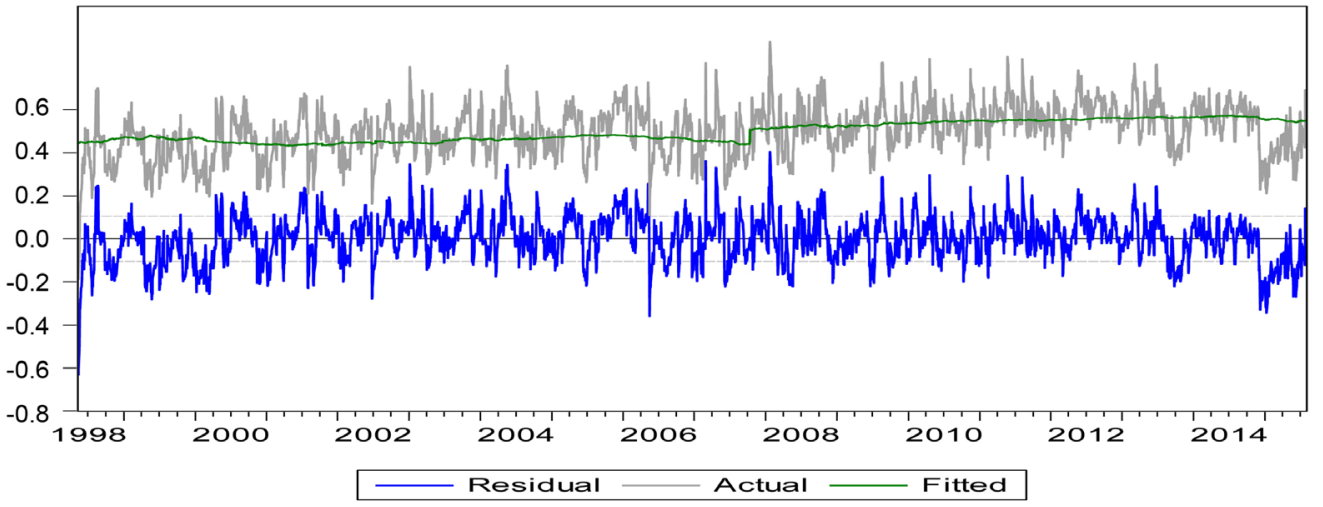

(c)

Figure 9. (a) Impact of QFII on DCC of stock returns: China (CN) and SE Asia (SEA). (b) LSTM estimates of DCC on stock returns: China (CN) and SE Asia (SEA). (c) LSTM-VIX estimates of DCC on stock returns: China (CN) and SE Asia (SEA).

markets, the right-hand-side variable is given by $\left[\log \left(\frac{P}{E}\right)_{C N . t}-\log \left(\frac{P}{E}\right)_{i . t}\right]$, since the Chinese market has a higher P/E ratio compared to other markets (20.429 in the US, 15.388 in EU, 14.713 in HK, and so on). ${ }^{12}$ The

\footnotetext{
${ }^{12}$ We did additional tests. First, we test the DCC between JP and US and the relative P/E ratio for the two markets; this yields a coefficient of $-0.045(t=17.13)$ and an R-squared of 0.06 . Second, we fit the model of the DCC of China (JP) and one-day lag of the US (EU) market on the corresponding $\mathrm{P} / \mathrm{E}$ ratio, which yields a comparable result. We did this because of the 12-hour difference in the open (and closed) trading hours between China (Japan) and the US and a bit shorter difference between China and the EU markets.
} 


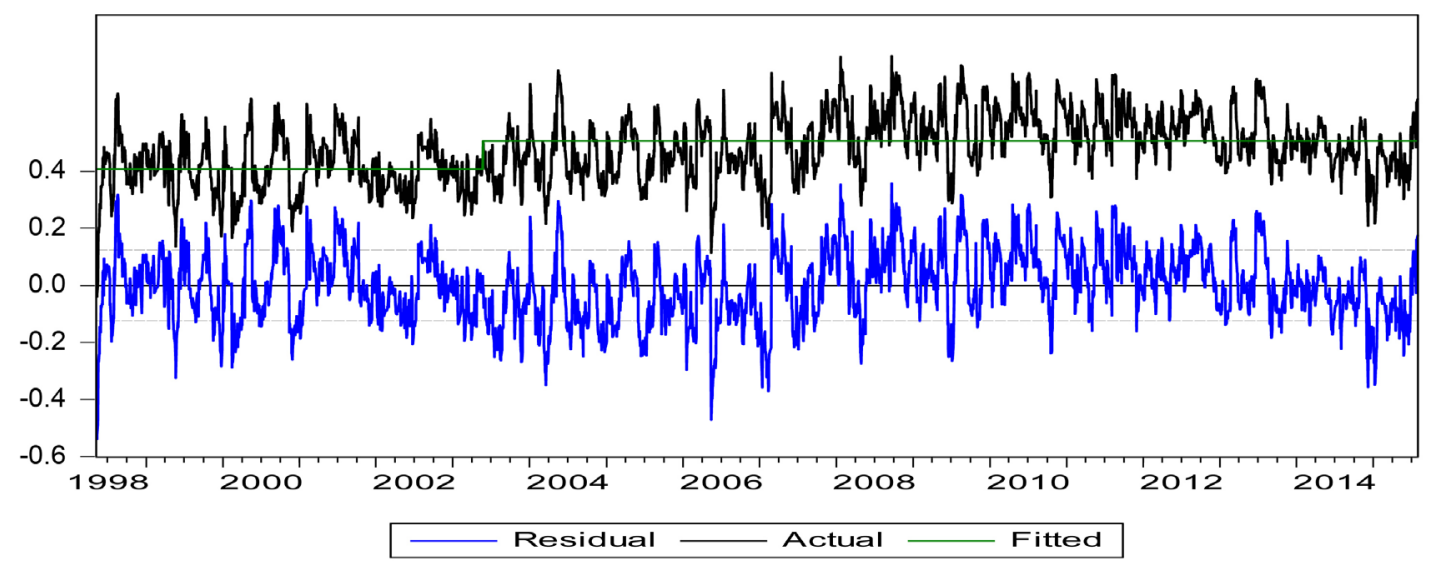

(a)

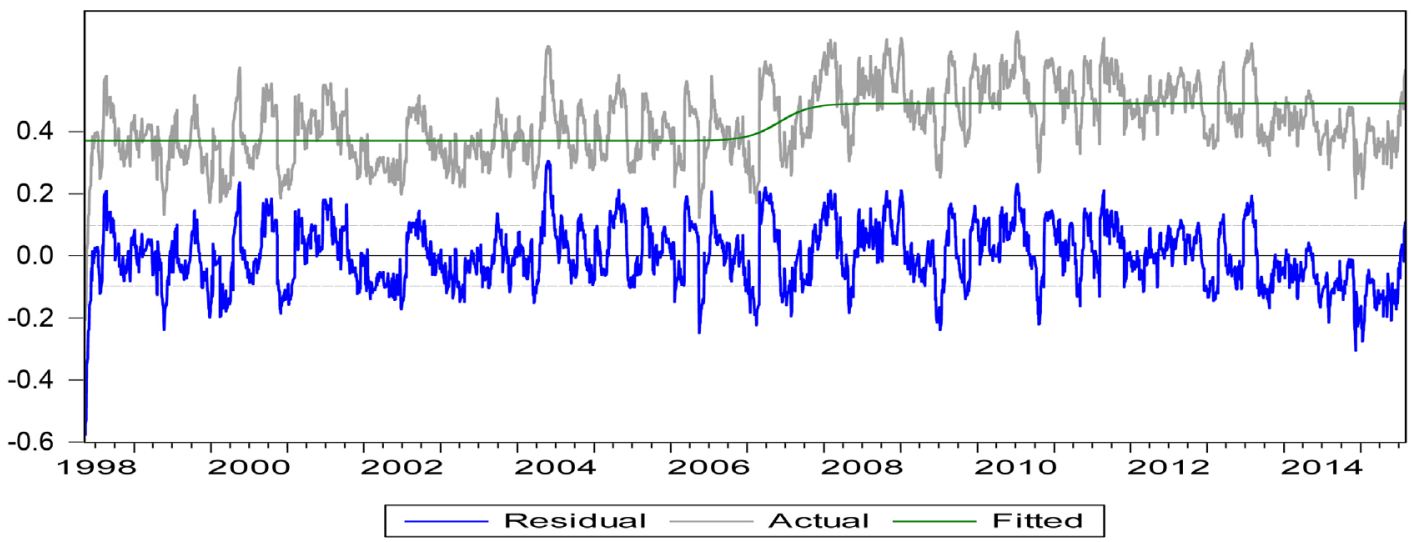

(b)

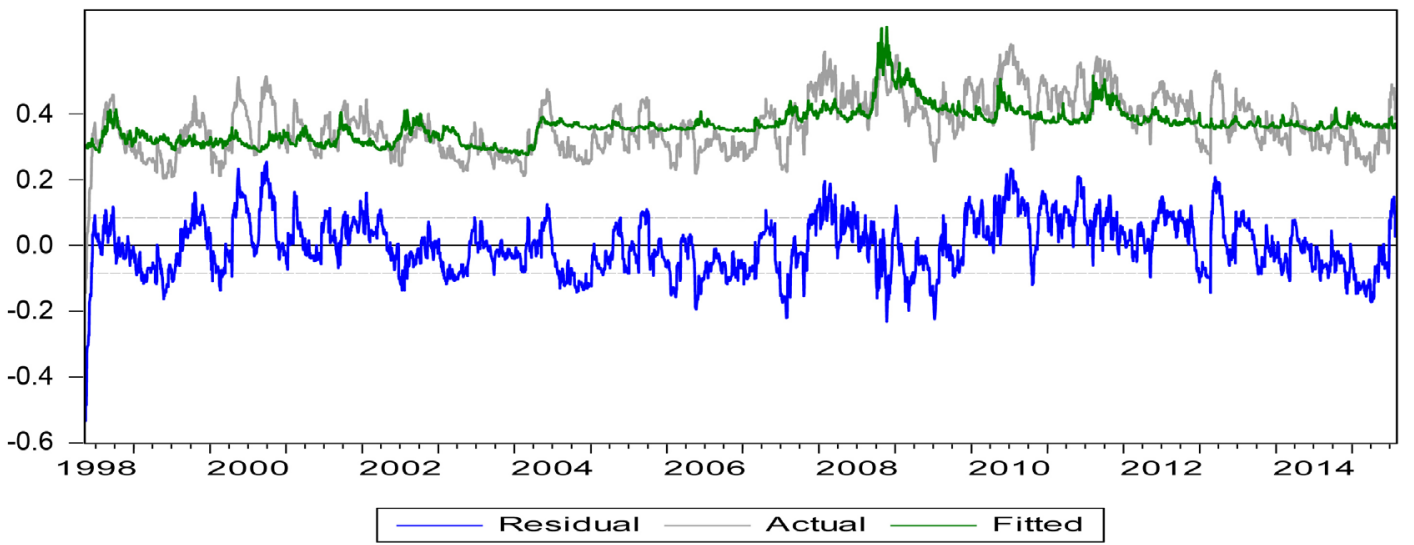

(c)

Figure 10. (a) Impact of QFII on DCC of stock returns: China (CN) and emerging (EM) markets. (b) LSTM estimates of DCC on stock returns: China (CN) and emerging (EM) markets. (c) LSTM-VIX estimates of DCC on stock returns: China $(\mathrm{CN})$ and emerging $(\mathrm{EM})$ markets.

evidence, therefore, conforms to the theoretical prediction and illustrates that the decoupling of stock returns is correlated with an increase in deviations of the P/E ratios of the two markets.

\subsection{Implied Volatility and Conditional Correlation Variations}

The path of fitting the conditional correlation series by using an LSTM, as in Figure 3(b)-Figure 10(b), and to 


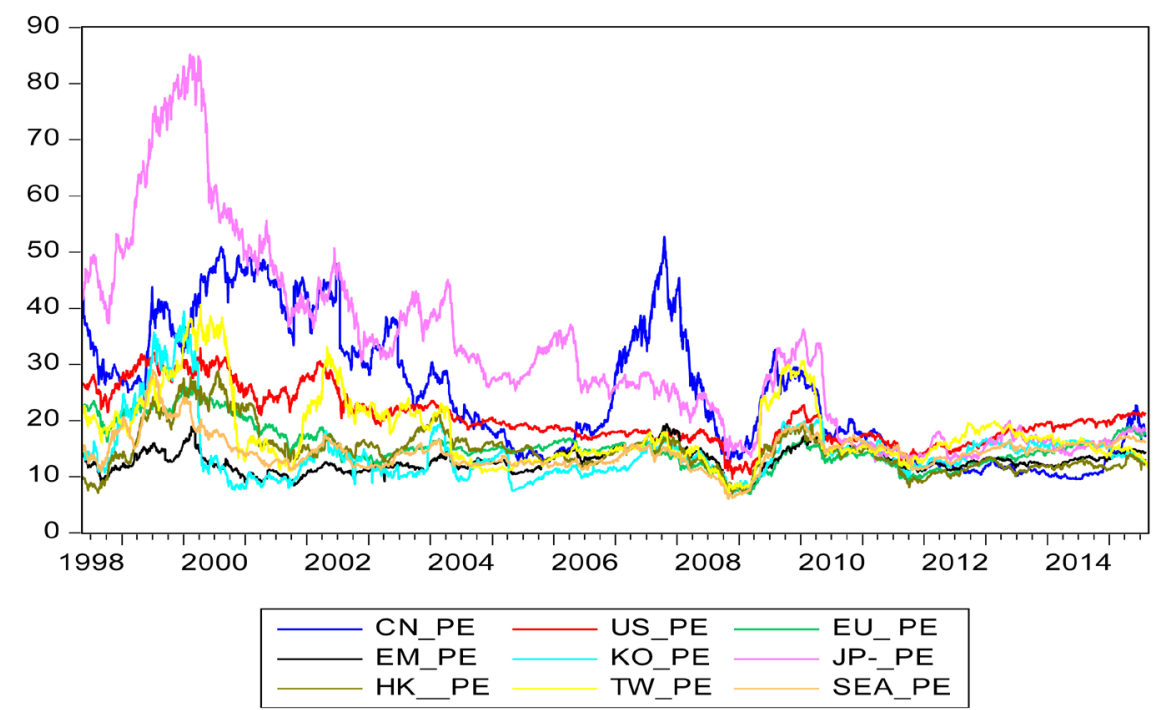

Figure 11. Time series plots of P/E ratios for different markets.

Table 6. Estimates of the conditional correlation of stock returns based on the relative $\log (P / E): 5 / 12 / 1998-7 / 31 / 2015$.

\begin{tabular}{ccccccccc}
\hline Markets & $\hat{\rho}_{C N, U S, t}$ & $\hat{\rho}_{C N, E U, t}$ & $\hat{\rho}_{C N, H K, t}$ & $\hat{\rho}_{C N, T W, t}$ & $\hat{\rho}_{C N I P, t}$ & $\hat{\rho}_{C N, K O, t}$ & $\hat{\rho}_{C N, S E A, t}$ & $\hat{\rho}_{C N, E M, t}$ \\
\hline \multirow{2}{*}{$C$} & $-0.043^{* * *}$ & $0.103^{* * *}$ & $0.399^{* * *}$ & $0.207^{* * *}$ & $0.167^{* * *}$ & $0.230^{* * *}$ & $0.255^{* * *}$ & $-0.283^{* * *}$ \\
& $(62.07)$ & $(54.67)$ & $(103.98)$ & $(46.39)$ & $(106.73)$ & $(91.99)$ & $(116.48)$ & $(117.60)$ \\
$\log \left(P E_{H, t} / P E_{L, t}\right)$ & $-0.051^{* * *}$ & $-0.0440^{* * *}$ & $-0.174^{* * *}$ & $-0.145^{* * *}$ & $-0.060^{* * *}$ & $-0.061^{* * *}$ & $-0.078^{* * *}$ & $-0.073^{* * *}$ \\
& $(29.89)$ & $(13.37)$ & $(26.47)$ & $(14.77)$ & $(15.31)$ & $(18.18)$ & $(23.55)$ & $(22.74)$ \\
$R^{2}$ & 0.17 & 0.04 & 0.13 & 0.29 & 0.05 & 0.07 & 0.11 & 0.10 \\
\hline
\end{tabular}

$\hat{\rho}_{C N, j, t}$ is the correlation coefficient between stock returns for market $C(\mathrm{CN})$ and $j(j=\mathrm{HK}, \mathrm{KR}, \mathrm{JP}, \mathrm{EU}, \mathrm{US})$ returns derived from the DCC model; The $\left[\log \left(\frac{P}{E}\right)_{H . t}-\log \left(\frac{P}{E}\right)_{L . t}\right]$ is the log-difference between the high and low P/E markets. Absolute values of $t$-statistics are given in parentheses. ${ }^{* * *},{ }^{* *}$, and ${ }^{*}$ denote statistical significance at the $1 \%, 5 \%$, and $10 \%$ levels, respectively. $\bar{R}^{2}$ is the adjusted $R^{2}$.

Table 7. A summary of statistics of dynamic correlations between China and international markets: 5/12/1998-7/31/2015.

\begin{tabular}{cccccccccc}
\hline & CN_PE & US_PE & EU_PE & HK_PE & TW_PE & JP_PE & KO_PE & SEA_PE & EM_PE \\
\hline Mean & 24.859 & 20.429 & 15.388 & 14.713 & 17.974 & 31.639 & 14.198 & 14.487 & 12.822 \\
Median & 21.900 & 19.300 & 14.900 & 14.200 & 15.900 & 27.700 & 13.300 & 14.300 & 12.700 \\
Maximum & 52.700 & 32.900 & 26.400 & 28.800 & 40.600 & 85.200 & 39.400 & 29.000 & 19.400 \\
Minimum & 9.500 & 9.600 & 6.900 & 6.400 & 6.900 & 12.700 & 6.900 & 6.000 & 7.000 \\
Std. Dev. & 11.755 & 4.737 & 3.745 & 3.951 & 6.195 & 16.757 & 5.136 & 3.106 & 2.034 \\
Skewness & 0.500 & 0.610 & 0.581 & 1.002 & 1.225 & 1.178 & 2.153 & 0.979 & 0.276 \\
Kurtosis & 2.012 & 2.695 & 3.275 & 4.160 & 4.236 & 4.010 & 8.680 & 6.278 & 3.285 \\
Jarque-Bera & 369.96 & 296.19 & 267.06 & 1004.63 & 1413.22 & 1230.57 & 9513.51 & 2730.28 & 72.22 \\
Probability & 0.00 & 0.00 & 0.00 & 0.00 & 0.00 & 0.00 & 0.00 & 0.00 & 0.00 \\
Sum Sq. Dev. & 620,870 & 100,823 & 63,030 & 70,137 & 172,906 & $1,261,661$ & 118,524 & 43,357 & 18,597 \\
Observations & 4494 & 4494 & 4494 & 4494 & 4506 & 4494 & 4494 & 4494 & 4494 \\
\hline
\end{tabular}


model regime shifts seems too smooth and fails to reflect ongoing variations in response to shocks. In the empirical literature, [31] demonstrates that changes in the correlation between markets is associated with changes in the conditional variance. [32] finds that correlations of asset returns are linked to the implied volatility of stocks. [33] further contends that the VIX can capture uncertainty arising from asset fundamentals or shifts in investor sentiment. ${ }^{13}$ In addition, it is generally recognized that stock markets in Asian markets are constantly influenced by the uncertainty from the US market; the 2007-2008 financial crisis is a typical example [34] [35]. With these thought processes, we shall incorporate the implied volatility of stocks (VIX) and the high-low P/E ratio into the LSTM, which is given by:

$$
\hat{\rho}_{i j, t}=\alpha+\beta S_{t}(\gamma, \tau)+\phi\left[\log \left(\frac{P}{E}\right)_{H . t}-\log \left(\frac{P}{E}\right)_{L . t}\right]+\delta(V I X)_{t}+v_{t}
$$

where $\hat{\rho}_{i, j, t}$ is the conditional correlation for markets $i$ (China) and $j$ (non-Chinese markets) after applying the Fisher transformation, and the $V I X_{t}$ is the implied volatility index from the US market [36]. $S_{t}(\gamma, \tau)$ is given by Equation (9); other notations are defined as before. The special feature of this specification is that the economic variables, such as the P/E ratio difference and the VIX, are incorporated into the LSTM and jointly describe the dynamic correlation behavior.

Table 8 reports the regression results of system Equations (11) and (9). The estimated parameters and related statistics perform well as shown by the higher values of the adjusted R-squares ranging from 0.21 to 0.81 . However, there are three points worth noting compared to the estimations in Table 5 and Table 6. First, the coefficients of the VIX are positive and statistically significant for all of the markets at the $1 \%$ level, except the US, which has a negative sign. These results indicate that the cross-market risk effects of non-US investors in

Table 8. Estimates of LSTM of dynamic correlations based on market data: 5/12/1998-7/31/2015.

\begin{tabular}{|c|c|c|c|c|c|c|c|c|c|}
\hline Markets & $\alpha$ & $\beta$ & $\gamma$ & $\tau$ & $\phi$ & $\delta$ & $\begin{array}{l}\text { Transition } \\
\text { midpoint }\end{array}$ & ADF statistic & $\bar{R}^{2}$ \\
\hline$\hat{\rho}_{C N, U S, t}$ & $\begin{array}{l}0.029^{* * *} \\
(21.79)\end{array}$ & $\begin{array}{l}0.089^{* * *} \\
(73.96)\end{array}$ & $\begin{array}{l}0.015^{* * *} \\
(10.72)\end{array}$ & $\begin{array}{l}0.623^{* * *} \\
(338.79)\end{array}$ & $\begin{array}{c}-0.021^{* * *} \\
(13.97)\end{array}$ & $\begin{array}{c}-0.0013^{* * *} \\
(20.28)\end{array}$ & 1/30/2009 & $-5.70^{* * *}$ & 0.67 \\
\hline$\hat{\rho}_{C N, E U, t}$ & $\begin{array}{l}0.093 \\
(0.79)\end{array}$ & $\begin{array}{l}0.094^{* * *} \\
(31.33)\end{array}$ & $\begin{array}{l}0.279 \\
(0.46)\end{array}$ & $\begin{array}{l}0.344^{* * *} \\
(804.59)\end{array}$ & $\begin{array}{l}-0.001 \\
(0.77)\end{array}$ & $\begin{array}{l}0.001^{* * * *} \\
(6.43)\end{array}$ & $4 / 12 / 2004$ & $-9.54^{* * *}$ & 0.21 \\
\hline$\hat{\rho}_{C N, H K, t}$ & $\begin{array}{c}0.085^{* * *} \\
(9.15)\end{array}$ & $\begin{array}{l}0.320^{* * *} \\
(38.02)\end{array}$ & $\begin{array}{l}0.003^{* * *} \\
(12.02)\end{array}$ & $\begin{array}{l}0.463^{* * *} \\
(103.38)\end{array}$ & $\begin{array}{c}-0.020^{* * *} \\
(2.67)\end{array}$ & $\begin{array}{l}0.003^{* * *} \\
(14.86)\end{array}$ & $5 / 01 / 2006$ & $-10.02^{* * *}$ & 0.61 \\
\hline$\hat{\rho}_{C N, T W, t}$ & $\begin{array}{l}0.054^{* * *} \\
(11.82)\end{array}$ & $\begin{array}{l}0.155^{* * *} \\
(37.51)\end{array}$ & $\begin{array}{l}0.004^{* * *} \\
(10.24)\end{array}$ & $\begin{array}{c}0.457^{* * *} \\
(81.32)\end{array}$ & $\begin{array}{c}-0.086^{* * *} \\
(23.28)\end{array}$ & $\begin{array}{l}0.003^{* * *} \\
(16.77)\end{array}$ & $8 / 10 / 2006$ & $-7.07^{* * *}$ & 0.60 \\
\hline$\hat{\rho}_{\text {CNIP }, t}$ & $\begin{array}{c}0.028^{* * *} \\
(6.24)\end{array}$ & $\begin{array}{l}0.072^{* * *} \\
(28.08)\end{array}$ & $\begin{array}{l}0.198 \\
(0.99)\end{array}$ & $\begin{array}{l}0.345^{* * *} \\
(265.09)\end{array}$ & $\begin{array}{c}-0.019^{* * *} \\
(4.94)\end{array}$ & $\begin{array}{l}0.004^{* * *} \\
(27.50)\end{array}$ & 4/19/2004 & $-13.13^{* * *}$ & 0.25 \\
\hline$\hat{\rho}_{C N, K O, t}$ & $\begin{array}{c}-0.026^{* * *} \\
(4.04)\end{array}$ & $\begin{array}{l}0.202^{* * *} \\
(36.18)\end{array}$ & $\begin{array}{l}0.004^{* * *} \\
(11.61)\end{array}$ & $\begin{array}{l}0.361^{* * *} \\
(56.37)\end{array}$ & $\begin{array}{l}0.004 \\
(1.05)\end{array}$ & $\begin{array}{l}0.005^{* * *} \\
(22.90)\end{array}$ & 7/27/2004 & $-9.72^{* * * *}$ & 0.81 \\
\hline$\hat{\rho}_{C N, S E A, t}$ & $\begin{array}{l}0.050^{* * *} \\
(29.37)\end{array}$ & $\begin{array}{l}0.078^{* * *} \\
(59.12)\end{array}$ & $\begin{array}{l}0.031^{* * *} \\
(10.61)\end{array}$ & $\begin{array}{l}0.411^{* * *} \\
(106.32\end{array}$ & $\begin{array}{c}-0.053^{* * *} \\
(36.87)\end{array}$ & $\begin{array}{c}0.007^{* * *} \\
(100.64)\end{array}$ & 6/07/2005 & $-15.04^{* * *}$ & 0.78 \\
\hline$\hat{\rho}_{C N, E M, t}$ & $\begin{array}{l}0.153^{* * *} \\
(35.98)\end{array}$ & $\begin{array}{l}0.095^{* * *} \\
(23.31)\end{array}$ & $\begin{array}{c}0.016^{* * *} \\
(4.06)\end{array}$ & $\begin{array}{l}0.512^{* * *} \\
(112.42)\end{array}$ & $\begin{array}{c}-0.037^{* * *} \\
(8.63)\end{array}$ & $\begin{array}{l}0.003^{* * *} \\
(15.57)\end{array}$ & 3/05/2007 & $-10.80^{* * * *}$ & 0.30 \\
\hline
\end{tabular}

a. This table presents the estimates of the logistic smooth transition regression model for the conditional correlation time series $\hat{\rho}_{i j, t}$ after applying the Fisher transformation. The model is given by $\hat{\rho}_{i j, t}=\alpha+\beta S_{t}(\gamma, \tau)+\phi\left[\log \left(\frac{P}{E}\right)_{H . t}-\log \left(\frac{P}{E}\right)_{L, t}\right]+\delta V I X_{t}+v_{t} \quad(11)$.

$S_{t}(\gamma, \tau)=(1+\exp (-\gamma(t-\tau T)))^{-1}, \tau>0$, (10), where the $\left[\log \left(\frac{P}{E}\right)_{H . t}-\log \left(\frac{P}{E}\right)_{L . t}\right]$ is the log-difference between the high and low P/E markets Absolute values oft-statistics are given in parentheses. b. ${ }^{* * *},{ }^{* *}$, and ${ }^{*}$ denote statistical significance at the $1 \%, 5 \%$, and $10 \%$ levels, respectively. $\bar{R}^{2}$ is the adjusted $R^{2}$.

${ }^{13}$ [37] observes that the Chicago Board Options Exchange (CBOE) volatility index (VIX) spikes during periods of market turmoil, reflecting market conditions: if expected market volatility increases (decreases), stock prices fall (rise), and investors require a higher (lower) rate of return to compensate for risk taking. 
response to the VIX tend to move in the same direction, although the magnitude of the different markets may vary slightly. However, the reaction of US investors relative to Chinese investors in response to the VIX is quite different owing to different attitudes and/or sentiments toward risk. Second, the evidence suggests that the estimated values of $\tau$ decline as the VIX is included in the test equation; now the values of $\tau$ range from 0.344 (Europe) to 0.623 (US), corresponding to the time period 4/12/2004-1/30/2009. This reflects the impact of the world financial crisis on the structural shift for each market, since the magnitude of the VIX is much greater during the crisis period. Purely relying on the LSTM without considering the VIX can lead to misspecification of the dynamic correlation function. Third, as shown in Figure 3(c)-Figure 10(c) and compared to the similar set of Figure 3(b)-Figure 10(b), including the VIX in the model helps to explain the variations as compared to the pure LSTM specification, indicating that the LSTM is too smooth to capture the reality of conditional correlation variations. ${ }^{14}$

\section{Summary and Conclusions}

This paper investigates the dynamic correlations between Chinese stock returns and those of six major and geographically close Asian partners-Hong Kong, Taiwan, South Korea, Japan, Southeastern Asia, and emerging markets plus two advanced markets- the US and Europe; the latter two markets are more geographically separated and have fewer traditional cultural ties. We derive several important empirical conclusions. First, empirical estimations based on an asymmetric dynamic correlation coefficient model (ADCC) indicate that all correlations are time-varying. Second, the dynamic correlations display a level shift or smooth transitional upward changes over time. The evidence confirms a structural change right after China's adoption of a higher degree of financial liberalization, such as China's admission to the WTO at the end of 2001 and the implementation of the QFII scheme beginning in 2003. However, the majority of the structural shifts were significantly influenced by the global financial crisis during the period 2007-2008.

Third, although China and Hong Kong have a stronger linkage, ${ }^{15}$ we also find that there are similar linkages within the Asian region. This finding is consistent with the geographic gravity hypothesis. However, the linkages of the Chinese stock market with the US and European markets are less significant. As a result, holding portfolios consisting of a combination of Chinese-US stocks or Chinese-European stocks helps to achieve international portfolio diversification.

Fourth, we also examine underlying factors that might explain the dynamic correlation coefficient of stock returns. The testing result suggests that the relative P/E ratios are significant. This finding suggests that the decoupling of stock returns in the two markets is associated with greater market uncertainty, as reflected in the divergence of the P/E ratios of the two markets. The evidence also suggests that the risk from the US market, as proxied by VIX from the US market, plays a significant role in explaining the dynamic correlation function. Thus, not incorporating the VIX into the smooth transitional model tends to generate biased estimates of the dynamic path.

\section{References}

[1] Liu, Y.A., Pan, M.-S. and Shieh, J. (1998) International Transmission of Stock Price Movements: Evidence from the US and Five Asian-Pacific Markets. Journal of Economics and Finance, 22, 59-69. http://dx.doi.org/10.1007/BF02823233

[2] Koch, P.D. and Koch, T.W. (1991) Evolution in Dynamic Linkages across Daily National Stock Indexes. Journal of International Money and Finance, 10, 231-251. http://dx.doi.org/10.1016/0261-5606(91)90037-K

[3] King, M. and Wadhwani, S. (1990) Transmission of Volatility between Stock Markets. Review of Financial Studies, 3, 5-33. http://dx.doi.org/10.1093/rfs/3.1.5

[4] Lee, S.B. and Kim, K.J. (1993) Does the October 1987 Crash Strengthen the Co-Movements among National Stock Markets? Review of Financial Economics, 3, 89-102.

[5] Forbes, K. and Rigobon, R. (2002) No Contagion, Only Interdependence: Measuring Stock Market Co-Movements. Journal of Finance, 57, 2223-2262. http://dx.doi.org/10.1111/0022-1082.00494

[6] Bordo, M. and Murshid, A. (2001) Are Financial Crises Becoming Increasingly More Contagious? What Is the Evi-

\footnotetext{
${ }^{14}$ Although relative $\mathrm{P} / \mathrm{E}$ ratio is also included in the test equation, the main variations are attributable to the VIX.

${ }^{15}$ Given the Shanghai-Hong Kong stock connect, we anticipate that the linkage between China and Hong Kong will further increase in the future.
} 
dence on Contagion? In: Claessens, S. and Forbes, K.J., Eds., International Financial Contagion, Kluwer Academic Press, Boston, 367-403. http://dx.doi.org/10.1007/978-1-4757-3314-3_14

[7] Engle, R. (2002) Dynamic Conditional Correlation: A Simple Class of Multivariate Generalized Autoregressive Conditional Heteroskedasticity Models. Journal of Business \& Economic Statistics, 20, 339-350. http://dx.doi.org/10.1198/073500102288618487

[8] Cappiello, L., Engle, R.F. and Sheppard, K. (2006) Asymmetric Dynamics in the Correlations of Global Equity and Bond Returns. Journal of Financial Econometrics, 4, 537-572. http://dx.doi.org/10.1093/jifinec/nbl005

[9] Chiang, T.C., Jeon, B.N. and Li, H. (2007) Dynamic Correlation Analysis of Financial Contagion: Evidence from Asian Markets. Journal of International Money and Finance, 26, 1206-1228. http://dx.doi.org/10.1016/j.jimonfin.2007.06.005

[10] Chiang, T.C., Tan, L. and Li, H. (2007) Empirical Analysis of Dynamic Correlations of Stock Returns: Evidence from Chinese A-Share and B-Share Markets. Quantitative Finance, 7, 651-667. http://dx.doi.org/10.1080/14697680601173147

[11] Baur, D.G. and Fry, R.A. (2009) Multivariate Contagion and Interdependence. Journal of Asian Economics, 20, 353366. http://dx.doi.org/10.1016/j.asieco.2009.04.008

[12] Kenourgios, D., Samitasb, A. and Paltalidisc, N. (2001) Financial Crises and Stock Market Contagion in a Multivariate Time-Varying Asymmetric Framework. Journal of International Financial Markets, Institutions and Money, 21, 92106. http://dx.doi.org/10.1016/j.intfin.2010.08.005

[13] Dungey, M., Fry, R., Gonzalez-Hermosillo, B. and Martin, V.L. (2005) Empirical Modeling of Contagion: A Review of Methodologies. Quantitative Finance, 5, 9-24. http://dx.doi.org/10.1080/14697680500142045

[14] Yu, I.-W., Fung, K.-P. and Tam, C.-S. (2010) Assessing Financial Market Integration in Asia—Equity Markets. Journal of Banking and Finance, 34, 2874-2885. http://dx.doi.org/10.1016/j.jbankfin.2010.02.010

[15] Masih, A. and Masih, R. (1999) Are Asian Market Fluctuations Due Mainly to Intra-Regional Contagion Effects? Evidence Based on Asian Emerging Stock Markets. Pacific-Basin Finance Journal, 7, 251-282. http://dx.doi.org/10.1016/S0927-538X(99)00013-X

[16] Zhu, H., Lu, Z. and Wang, S. (2004) Causal Linkages among Shanghai, Shenzhen, and Hong Kong Stock Markets. International Journal of Theoretical and Applied Finance, 7, 135-149. http://dx.doi.org/10.1142/S0219024904002414

[17] Qiao, Z., Chiang, T.C. and Wong, W.-K. (2008) Long-Run Equilibrium, Short-Term Adjustment, and Spillover Effects across Chinese Segmented Stock Markets and the Hong Kong Stock Market. Journal of International Financial Markets, Institutions \& Money, 18, 425-437. http://dx.doi.org/10.1016/j.intfin.2007.05.004

[18] Zhang, S., Paya, I. and Peel, D. (2009) Linkages between Shanghai and Hong Kong Stock Indices. Applied Financial Economics, 19, 1847-1857. http://dx.doi.org/10.1080/09603100903085066

[19] Chow, G.C. and Lawler, C.C. (2003) A Time Series Analysis of Shanghai and New York Stock Price Indices. Annals of Economics and Finance, 4, 17-35.

[20] Chiang, T.C., Lao, L. and Xue, Q. (2015) Co-Movements between Chinese and Global Stock Markets: Evidence from Aggregate and Sectoral Data. Review of Quantitative Finance and Accounting, 17, 1-40. http://link.springer.com/article/10.1007/s11156-015-0529-x http://dx.doi.org/10.1007/s11156-015-0529-x

[21] Black, F. (1976) Studies of Stock Price Volatility Changes. In: Proceedings of the 1976 Meeting of the Business and Economic Statistics Section, American Statistical Association, Washington DC, 177-181.

[22] Christie, A.A. (1982) The Stochastic Behavior of Common Stock Variances-Value, Leverage and Interest Rate Effects. Journal of Financial Economics, 10, 407-432. http://dx.doi.org/10.1016/0304-405X(82)90018-6

[23] Tam, O.K., Li, S.G., Zhang, Z. and Yu, C.P. (2010) Foreign Investment in China and Qualified Foreign Institutional Investor (QFII). Asian Business and Management, 9, 425-448. http://dx.doi.org/10.1057/abm.2010.15

[24] Box, G.E.P. and Tiao, G.C. (2006) Intervention Analysis with Applications to Economic and Environment Problems. Journal of American Statistical Association, 70, 70-79. http://dx.doi.org/10.1080/01621459.1975.10480264

[25] Stulz, R.M. (1999) Globalization of Equity Markets and the Cost of Capital. NBER Working Paper 7021. http://dx.doi.org/10.2139/ssrn.153669

[26] Leybourne, S., Newbold, P. and Vougas, D. (1998) Unit Roots and Smooth Transitions. Journal of Time Series Analysis, 19, 83-97. http://dx.doi.org/10.1111/1467-9892.00078

[27] Lahrech, A. and Sylwester, K. (2011) US and Latin American Stock Market Linkages. Journal of International Money and Finance, 30, 1341-1357. http://dx.doi.org/10.1016/j.jimonfin.2011.07.004

[28] Teräsvirta, T. and Anderson, H.M. (1992) Characterizing Nonlinearities in Business Cycles Using Smooth Transition Autoregressive Models. Journal of Applied Econometrics, 7, 119-136. 
[29] Phylaktis, K. and Xia, L. (2009) Equity Market Co-Movement and Contagion: A Sectoral Perspective. Financial Management, 38, 381-409. http://dx.doi.org/10.1111/j.1755-053X.2009.01040.X

[30] Corsetti, G., Pericoli, M. and Sbracia, M. (2005) Some Contagion, Some Interdependence: More Pitfalls in Tests of Financial Contagion. Journal of International Money and Finance, 24, 1177-1199. http://dx.doi.org/10.1016/j.jimonfin.2005.08.012

[31] Longin, F. and Solnik, B. (1995) Is the Correlation in International Equity Returns Constant: 1960-1990? Journal of International Money and Finance, 14, 3-26. http://dx.doi.org/10.1016/0261-5606(94)00001-H

[32] Connolly, R.A., Stivers, C.T. and Sun, L. (2005) Stock Market Uncertainty and the Stock-Bond Return Relation. Journal of Financial and Quantitative Analysis, 40, 161-194. http://dx.doi.org/10.1017/S0022109000001782

[33] Hakkio, C. and Keeton, W.R. (2009) Financial Stress: What Is It, How Can It Be Measured, and Why Does It Matter? Economic Review, 2, 5-50.

[34] Cheng, A.R., Jahan-Parvar, M.R. and Rothman, P. (2014) Risk-Return Trade-Off in the Pacific Basin Equity Markets. Emerging Markets Review, 18, 123-140. http://dx.doi.org/10.1016/j.ememar.2014.01.004

[35] Cheung, W., Fung, S. and Tsai, S. (2010) Global Capital Market Interdependence and Spillover Effect of Credit Risk: Evidence from the 2007-2009 Global Financial Crisis. Applied Financial Economics, 20, 85-103. http://dx.doi.org/10.1080/09603100903262962

[36] Whaley, R.E. (2009) Understanding the VIX. Journal of Portfolio Management, 35, 98-105. http://dx.doi.org/10.3905/JPM.2009.35.3.098

[37] Lau, K., Moe, T., Bei, B. and Liu, C. (2014) The “New” Investment Case for China for Global/A Share Investors. Goldman Sachs portfolio Strategy Research, September 11. 


\section{Appendix 1. Chinese Interest Rate Policy on Dynamic Conditional Correlations}

It is generally recognized that the Chinese stock markets are highly influenced by government policies. To this end, we consider the tightness of the monetary policy implemented by the People's Bank of China, the central bank of China. ${ }^{16}$ We divide the monetary policy data into two categories: easy monetary policy and tight monetary policy. Using an indicator variable, we set the indicator variable to be unity for the policy change, otherwise, zero. By so doing, we rewrite Equation (10) as:

$$
\hat{\rho}_{i, j, t}=\phi_{0}+\phi_{1}\left[\log \left(\frac{P}{E}\right)_{C N . t}-\log \left(\frac{P}{E}\right)_{i, t}\right]+\phi_{2} I_{U, t}+\phi_{3} I_{D, t}+\varepsilon_{t}
$$

where $I_{U, t}$ is an indicator for rate up (tight monetary policy), and $I_{U, t}$ for rate down (easy monetary policy), and other variables are defined in the same way as before. The estimated results are reported in Table A. The evidence suggests that the relative P/E continues to have a similar qualitative effect and exhibits statistical significance. With respect to the effect of monetary policy, we find that tight monetary policy $\left(I_{U, t}\right)$ more consistently influences the dynamic correlation. The evidence shows that all of the coefficients have positive signs and are statistically significant for six out of eight markers; the EU and JP are less significant. However, these two markets turn out to be more significant in the easy monetary policy regime $\left(I_{D, t}\right)$ in China. Among different markets, only the Hong Kong market displays sensitivity and a positive sign, and is significant under both tight and easy monetary policy. This can also be because Hong Kong has much closer ties to the Chinese market, especially in the period after the establishment of the Shanghai-Hong Kong stock connect on November 17, 2014 (see [37]).

Table A. Estimates of the conditional correlation of stock returns based on the relative $\log (P / E)$ and easiness of monetary policy.

\begin{tabular}{|c|c|c|c|c|c|c|c|c|}
\hline Markets & $\hat{\rho}_{C N, U S, t}$ & $\hat{\rho}_{C N, E U, t}$ & $\hat{\rho}_{C N, H K, t}$ & $\hat{\rho}_{C N, T W, t}$ & $\hat{\rho}_{C N I P, t}$ & $\hat{\rho}_{C N, K O, t}$ & $\hat{\rho}_{C N, S E A, t}$ & $\hat{\rho}_{C N, E M, t}$ \\
\hline$C$ & $\begin{array}{l}0.043^{* * *} \\
(19.65)\end{array}$ & $\begin{array}{l}0.109^{* * *} \\
(21.34)\end{array}$ & $\begin{array}{c}0.399^{* * *} \\
(103.98)\end{array}$ & $\begin{array}{l}0.207^{* * *} \\
(46.39)\end{array}$ & $\begin{array}{l}0.167^{* * *} \\
(106.19)\end{array}$ & $\begin{array}{l}0.23^{* * *} \\
(33.31)\end{array}$ & $\begin{array}{l}0.256^{* * *} \\
(44.89)\end{array}$ & $\begin{array}{l}0.287^{* * *} \\
(39.14)\end{array}$ \\
\hline $\log \left(P E_{C N, t} / P E_{i, t}\right)$ & $\begin{array}{c}-0.052^{* * *} \\
(12.14)\end{array}$ & $\begin{array}{c}-0.092^{* * *} \\
(6.82)\end{array}$ & $\begin{array}{c}-0.175^{* * *} \\
(26.47)\end{array}$ & $\begin{array}{c}-0.145^{* * *} \\
(14.90)\end{array}$ & $\begin{array}{c}0.060^{* * *} \\
(15.22)\end{array}$ & $\begin{array}{c}-0.032^{* * *} \\
(7.92)\end{array}$ & $\begin{array}{c}-0.003^{* * *} \\
(9.05)\end{array}$ & $\begin{array}{c}-0.086^{* * *} \\
(8.89)\end{array}$ \\
\hline$I_{U, t}$ & $\begin{array}{c}0.069^{* * *} \\
(4.68)\end{array}$ & $0.042(1.29)$ & $\begin{array}{c}0.163^{* * *} \\
(4.54)\end{array}$ & $\begin{array}{c}0.123^{* * *} \\
(5.354)\end{array}$ & $\begin{array}{l}0.001 \\
(0.05)\end{array}$ & $\begin{array}{l}0.092^{* *} \\
(2.58)\end{array}$ & $\begin{array}{l}0.044^{*} \\
(1.69)\end{array}$ & $\begin{array}{c}0.081^{* * *} \\
(3.53)\end{array}$ \\
\hline$I_{D, t}$ & $\begin{array}{c}-0.014 \\
(1.57)\end{array}$ & $\begin{array}{c}0.026^{* * *} \\
(54.67)\end{array}$ & $\begin{array}{c}0.152^{* * *} \\
(3.35)\end{array}$ & $\begin{array}{l}0.043 \\
(1.39)\end{array}$ & $\begin{array}{c}0.073^{* * *} \\
(2.71)\end{array}$ & $\begin{array}{l}0.060 \\
(1.41)\end{array}$ & $\begin{array}{l}0.013 \\
(0.31)\end{array}$ & $\begin{array}{l}0.049 \\
(1.12)\end{array}$ \\
\hline $\bar{R}^{2}$ & 0.17 & 0.07 & 0.14 & 0.30 & 0.05 & 0.09 & 0.11 & 0.11 \\
\hline
\end{tabular}

a. $\quad \hat{\rho}_{C N, j, t}$ is the conditional correlations for China market and $j$ (international) market. the $\left[\log \left(\frac{P}{E}\right)_{H . t}-\log \left(\frac{P}{E}\right)_{L . t}\right]$ is the relative P/E ratio between high and low market in a log-form. Absolute values of $t$-statistics are given in parentheses where $I_{U, t}$ is an indicator for rate up (tight monetary policy), and $I_{U, t}$ for rate down (easy monetary policy). ${ }^{* * *},{ }^{* *}$, and ${ }^{*}$ denote statistical significance at the $1 \%, 5 \%$, and $10 \%$ levels, respectively. $\bar{R}^{2}$ is the adjusted $R^{2}$. 